University of Wollongong

Research Online

Australian Institute for Innovative Materials -

Papers

Australian Institute for Innovative Materials

$1-1-2019$

Quantitative ultrasound imaging of cell-laden hydrogels and printed constructs

Andres Ruland Palaia

University of Wollongong, ruland@uow.edu.au

Kerry J. Gilmore

University of Wollongong, kerryg@uow.edu.au

Luciana Daikuara

University of Wollongong, lyd866@uowmail.edu.au

Cormac Fay

University of Wollongong, cfay@uow.edu.au

Zhilian Yue

University of Wollongong, zyue@uow.edu.au

See next page for additional authors

Follow this and additional works at: https://ro.uow.edu.au/aiimpapers

Part of the Engineering Commons, and the Physical Sciences and Mathematics Commons

Research Online is the open access institutional repository for the University of Wollongong. For further information contact the UOW Library: research-pubs@uow.edu.au 


\title{
Quantitative ultrasound imaging of cell-laden hydrogels and printed constructs
}

\begin{abstract}
In the present work we have revisited the application of quantitative ultrasound imaging (QUI) to cellular hydrogels, by using the reference phantom method (RPM) in combination with a local attenuation compensation algorithm. The investigated biological samples consisted of cell-laden collagen hydrogels with PC12 neural cells. These cell-laden hydrogels were used to calibrate the integrated backscattering coefficient (IBC) as a function of cell density, which was then used to generate parametric images of local cell density. The image resolution used for QUI and its impact on the relative IBC error was also investigated. Another important contribution of our work was the monitoring of PC12 cell proliferation. The cell number estimates obtained via the calibrated IBC compared well with data obtained using a conventional quantitative method, the MTS assay. Evaluation of spectral changes as a function of culture time also provided additional information on the cell cluster size, which was found to be in close agreement with that observed by microscopy. Last but not least, we also applied QUI on a 3D printed cellular construct in order to illustrate its capabilities for the evaluation of bioprinted structures. Statement of Significance: While there is intensive research in the areas of polymer science, biology, and $3 \mathrm{D}$ bio-printing, there exists a gap in available characterisation tools for the non-destructive inspection of biological constructs in the three-dimensional domain, on the macroscopic scale, and with fast data acquisition times. Quantitative ultrasound imaging is a suitable characterization technique for providing essential information on the development of tissue engineered constructs. These results provide a detailed and comprehensive guide on the capabilities and limitations of the technique.
\end{abstract}

\section{Disciplines}

Engineering | Physical Sciences and Mathematics

\section{Publication Details}

Ruland , A., Gilmore, K. J., Daikuara, L. Y., Fay, C. D., Yue, Z. \& Wallace, G. G. (2019). Quantitative ultrasound imaging of cell-laden hydrogels and printed constructs. Acta Biomaterialia, 91 173-185.

\section{Authors}

Andres Ruland Palaia, Kerry J. Gilmore, Luciana Daikuara, Cormac Fay, Zhilian Yue, and Gordon G. Wallace 


\title{
Quantitative Ultrasound Imaging of Cell-laden Hydrogels and Printed Constructs
}

Andres Ruland $^{1}$, Kerry J. Gilmore ${ }^{1}$, Luciana Y. Daikuara, Cormac D. Fay, Zhilian Yue, and Gordon G. Wallace*

ARC Centre of Excellence for Electromaterials Science (ACES), Intelligent Polymer Research Institute, AIIM Facility, Innovation Campus, University of Wollongong, Australia

*Corresponding author: G. G. Wallace, Email: gwallace@uow.edu.au

${ }^{1}$ These authors contributed equally to this work.

\begin{abstract}
In the present work we have revisited the application of quantitative ultrasound imaging (QUI) to cellular hydrogels, by using the reference phantom method (RPM) in combination with a local attenuation compensation algorithm. The investigated biological samples consisted of cell-laden collagen hydrogels with PC12 neural cells. These cell-laden hydrogels were used to calibrate the integrated backscattering coefficient (IBC) as a function of cell density, which was then used to generate parametric images of local cell density. The image resolution used for QUI and its impact on the relative IBC error was also investigated. Another important contribution of our work was the monitoring of PC12 cell proliferation. The cell number estimates obtained via the calibrated IBC compared well with data obtained using a conventional quantitative method, the MTS assay. Evaluation of spectral changes as a function of culture time also provided additional information on the cell cluster size, which was found to be in close agreement with that observed by microscopy. Last but not least, we also applied QUI on a 3D printed cellular construct in order to illustrate its capabilities for the evaluation of bioprinted structures.
\end{abstract}

Keywords: Quantitative ultrasound imaging, biomaterial characterization, cellular hydrogels, bio-printing. 


\section{Statement of significance}

While there is intensive research in the areas of polymer science, biology, and 3D bioprinting, there exists a gap in available characterisation tools for the non-destructive inspection of biological constructs in the three-dimensional domain, on the macroscopic scale, and with fast data acquisition times. Quantitative ultrasound imaging is a suitable characterization technique for providing essential information on the development of tissue engineered constructs. These results provide a detailed and comprehensive guide on the capabilities and limitations of the technique.

\section{Graphical abstract}

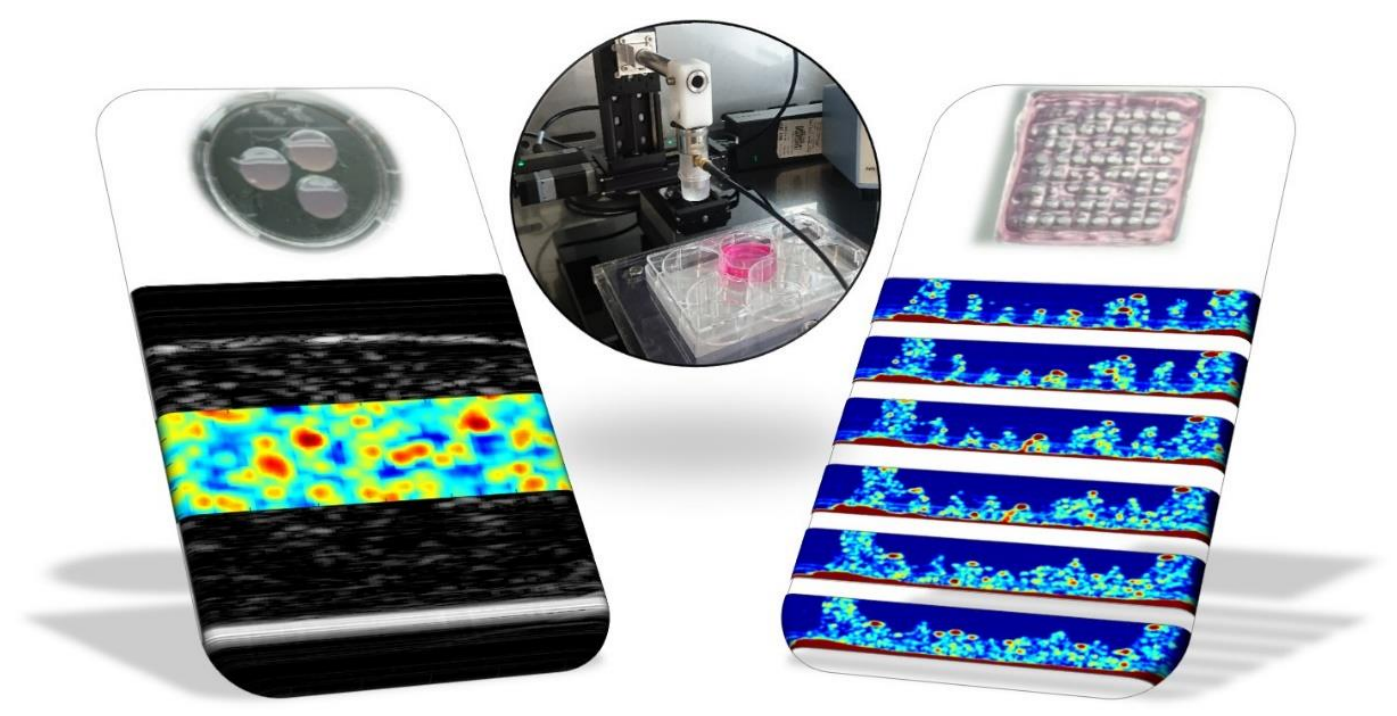

\section{Introduction}

Bio-printing and its application to tissue engineering is a fast growing field, as it allows researchers to recreate in vitro 3D biological constructs that mimic those from natural origin,[1] with the prospect of being implantable into living beings. As such, there is intense research in areas such as cartilage regeneration,[2] wound healing,[3] neural tissue models, [4] [5] and tissue vascularization[6] among others. In order to recreate 3D biological constructs, cells are encapsulated into printed or cast hydrogels, and matured over time until the construct possess the desired properties. A common challenge across the related areas, is the need to monitor the spatiotemporal evolution of 3D cellular constructs over time with a non-destructive and noninvasive approach. Relevant biological characterization features of the construct are for example, the monitoring of cell migration, changes in cell cluster size, cell proliferation, and/or 
differentiation. Biological constructs require sterile conditions during their culture and evaluation, and ideally, should be measured in situ without sample conditioning. Therefore, a characterisation tool which allows rapid monitoring of the biological construct is needed, either for quality control purposes or for the evaluation of diverse exogenous inputs for enhancing some biological factors. These may include monitoring of cell stimulation, effects of growth factors or drug screening.

Biological characterization can be in the form of nominal values, or as $2 \mathrm{D}$ or 3D parametric images. Techniques with imaging capabilities have an additional level of information, as they allow the spatial visualization of biological properties within the construct. In terms of imaging , a range of non-invasive techniques are available.[7] [8] [9] Comparison of the imaging capabilities of diverse non-invasive techniques can be found elsewhere. [7] [10] Based on its non-destructive character, optical microscopy, including all its variants such as confocal microscopy, are considered the gold standard for the assessment of biological constructs.[10] Optical characterisation offers the possibility of qualitative and quantitative analysis of cells within constructs, though it becomes challenging at high cell densities or in highly scattering samples. The use of optical clearing protocols has improved the scattering limitations.[11] Other drawbacks are the limited depth of view (below $1 \mathrm{~mm}$ ) [10] and the use of fluorescent markers which may be detrimental or destructive to living cells. Spectroscopic methods offer an alternative to optical characterization, with the advantage that they are non-destructive and label-free. Fourier transform infrared spectroscopy and imaging are widely used for cartilage evaluation, via the quantification of collagen, water and proteoglycans.[12] [13] [14] Raman spectroscopy allows a much more detailed spectral analysis without the interference of water. Raman spectroscopy has been used successfully for probing cell differentiation in several biological systems.[15] [16] In a recent study, the Raman technique was proven to reveal 3D images of individual cells within hydrogels at high resolution, with the possibility to isolate different intracellular structures as a function of their composition.[17] Other non-invasive imaging techniques are MRI and $\mu-\mathrm{CT}$, however they require the use of markers to enhance image contrast and discriminate investigated tissue from the background.[7] Based on their resolution, confocal microscopy, and more recently, Raman are therefore some of the most widely used characterization techniques to follow single cell behaviour and differentiation. The downside to the high resolution is the image acquisition time, as it becomes impractical when evaluating 3D constructs in the millimetre range. Hence, it would be ideal to not only monitor 
specific regions of the construct over time, but also in the macroscopic scale, on combination with a relatively narrow spatial resolution.

A viable characterisation technique for proving small spatiotemporal changes in $3 \mathrm{D}$ constructs can be found with ultrasound. A number of excellent reviews summarise most of the work carried out with ultrasound in the area of tissue engineering and related fields, with examples of applications in in vitro and in vivo studies.[7] [18] [19] [20] [21] One of the advantages of ultrasound is the possibility to extract quantitative information from the time and frequency domains of the measured radiofrequency (RF) signals, in a label-free and non-destructive approach. Analysis of the ultrasound radiofrequency (RF) signals in the time domain, such as the hydrogel thickness and speed of sound, are important as they are related to the mechanical properties of the construct.[22] [23] [24] Photoacoustic imaging (PAI) is a variation of ultrasound, that is under rapid development in biomedical applications.[25] [26] PAI is based on the ultrasonic detection of acoustic waves induced by the absorption of pulsed or modulated laser radiation (e.g. near infrared). While it is a measurement of high specificity, it requires the interrogated tissue to have a different absorption coefficient to the surrounding tissue or hydrogel matrix. This requires the presence of endogenous markers such as melanin or haemoglobin, or the use of exogenous markers such as nanoparticles or dyes.[27] [28] [29] The benefit of PAI over optical imaging is that it overcomes the optical diffraction limit in terms of imaging depth, where the image resolution and penetration depth are given by the ultrasound transducer's properties.[30] Other advanced techniques, such as ultrasound elastography, involves the use of a specific sequence of ultrasound pulses allowing the spatial mapping of the mechanical properties within a construct.[31, 32] [33]

In combination with conventional greyscale imaging, spectral analysis of high-frequency $(>20$ $\mathrm{MHz}$ ) ultrasound has been useful to detect a wide range of key parameters relevant to biological properties. This approach is termed as quantitative ultrasound or quantitative ultrasound imaging (QUI) when generating parametric images in 2D or 3D. QUI differentiates from conventional ultrasound imaging since the processed RF signals are power and attenuation compensated, and are system and user independent. QUI is less specific than PAI, but considers the scattering property of the construct as a whole. The use of quantitative procedures allows the sensing of sub-resolution scatters such as cells. Changes in the extracellular matrix composition due to tissue maturation are also possible to detect. For instance, single point attenuation measurements have been used for monitoring cartilage development.[34] Backscattered sound (power and attenuation compensated) has been proven to be linearly 
dependent on the cell density of cell-laden hydrogels. [35] [36] Mid-band-fit and spectral slope, which are other parameters to interpret backscattered spectra, have been used to detect changes due to cell death.[37] [38] Monitoring of calcium deposition by ultrasound, as an indirect approach to detect osteoblast differentiation in hydrogels, has also been demonstrated. [39] [40] The use of theoretical models to relate the spectral shape to the scatter morphology and concentration is another broad field of research.[41] [42] [43] For instance, spectral modelling has been used for single cells, [44] diagnosis of tumour cells, [45] [46] human thyroids, [47] and for the diagnosis of red blood cells, in terms of coagulation.[48] [49] One of the drawbacks in QUI, and perhaps the limiting factor for its application in tissue engineering, is the trade-off between image resolution and bias error on the derived ultrasound estimates. The latter originates from the spectral analysis, as it is done by the averaging of RF signals over specific volumetric dimensions within the sample, or in terms of pixel dimensions when referring to single scanning planes.

The goal of this study was to further develop the application of QUI to cell-laden hydrogels, with focus on the spectral cell resolution, and the validation of ultrasound in comparison to a common biochemical assay for cell density estimation. With the aim to use QUI to monitor spatiotemporal changes in small 3D constructs, we exploited the capability of QUI in conjunction with precision stage controllers to follow specific cross-sectional imaging planes of the construct over time. In addition to cell density estimates, we also monitored the evolution of cell growth in terms of spectral changes in relation to scatter size. Finally, we also applied our QUI procedure to bio-printed scaffolds as an illustration of the capabilities of ultrasound for characterisation in the field of bio-printing. As biological samples, we have investigated cell-laden type I collagen hydrogels with PC12 neural cells, in the concentration range from $0.5-8.0 \times 10^{6}$ cells $/ \mathrm{ml}$. In addition, gelatin methacryloyl hydrogel in combination with human dermal fibroblast were used for creating a 3D bioprinted construct. The choice of collagen was due to its ease of preparation and consistent hydrogel properties, while PC12 cells were used as a model system due to their ease of harvest, rapid proliferation, and clustering behaviour during growth. 


\section{Materials and methods}

\subsection{Cell-laden hydrogel preparation}

PC12 cells were kindly supplied by Professor Mark Wilson at the University of Wollongong and were originally sourced from the ATCC (USA). For the preparation of PC12 cell-laden hydrogels of specific cell densities, $0.5-8.0 \times 10^{6}$ cells $/ \mathrm{ml}$, cells were first manually counted using a haemocytometer to yield a stock solution. Known numbers of PC12 cells where then distributed into centrifuge vials, centrifuged and the resulting cell pellet was resuspended in the collagen precursor solution. The hydrogel precursor solution was made from rat tail collagen type I (Invitrogen) at a concentration of $2 \mathrm{mg} / \mathrm{ml}$ in DMEM and neutralised with 0.1 $\mathrm{N} \mathrm{NaOH}$. The precursor solution was kept on ice to avoid crosslinking. Once PC12 cells were finely suspended in the hydrogel precursor (e.g. without visible aggregates), $110 \mu \mathrm{l}$ aliquots for each cell density were distributed into moulds. The moulds consisted of a $2 \mathrm{~mm}$ thick acrylic plate with 3 wells of $8 \mathrm{~mm}$ diameter, attached to the bottom of 6-well culture plate. The culture plates were transferred immediately to an incubator at $37^{\circ} \mathrm{C}$ for 1 hour to allow crosslinking to take place. Crosslinked hydrogels were then gently flooded with cell proliferation media (GM, DMEM containing 10\% horse serum and 5\% foetal bovine serum and penicillin/streptomycin) and brought to room temperature before ultrasound measurements were taken. An example of the cross-linked cell-laden collagen samples prepared for this work can be seen in Fig. 1d.

\subsection{Bioprinted hydrogel preparation}

Gelatin methacryloyl (GelMA) at a concentration of $15 \%$ w/v was dissolved in the complete cell culture medium for Human dermal fibroblast (HDF) cells. HDF cells, obtained from Cell Applications, Inc. (USA), were cultured as previously reported.[50] Prior to cell printing, LAP photoinitiator was added to the ink with a final concentration of $0.06 \%(w / w)$, and HDFs were added with a final cell density of $1.0 \times 10^{6}$ cells $/ \mathrm{ml}$. Cell printing was conducted using a pneumatic extrusion-based 3D printer (3D Bioplotter, EnvisionTEC). A 3D cuboid model was designed through SolidWorks ${ }^{\mathrm{TM}}$ (Waltham), and exported as an STL file and sliced into layers at the Bioplotter $\mathrm{RP}^{\circledR}$ software. The 3D HDFs-containing constructs were fabricated layer by layer in a dimension of $10 \mathrm{~mm} \times 10 \mathrm{~mm} \times 2 \mathrm{~mm}(\mathrm{~W} \cdot \mathrm{L} \cdot \mathrm{H})$ with $0^{\circ} / 90^{\circ}$ crosshatch pattern. A set of printing parameters were employed, including ink cartridge temperature $\left(18^{\circ} \mathrm{C}\right)$, platform temperature $\left(13^{\circ} \mathrm{C}\right)$, plotting speed $(10.0 \mathrm{~mm} / \mathrm{s})$, pneumatic pressure $(3.6 \mathrm{bar})$, disposable needle tip $(200 \mu \mathrm{m})$, and strand spacing $(1.0 \mathrm{~mm})$. After printing, the 3D printed structures 
were chemically crosslinked using a UV light of $400 \mathrm{~nm}$ wavelength $\left(13.2 \mathrm{~mW} / \mathrm{cm}^{2}\right.$ for 60 seconds). The resulting bio-printed construct can be seen on Fig. 1c.

A portion of the HDF-GelMA formulation used for bioprinting was used to prepare a cast hydrogel, serving as the reference phantom for the bioprinted sample. The same crosslinking conditions were used as for the bioprinted sample. In order to hold the hydrogel on the surface, while allowing in it swell freely, the hydrogel was crosslinked around a small hook attached to the sample holder surface.

\subsection{MTS assay for cell density estimation}

The overall metabolic activity of encapsulated cells in both cell density calibration and cell proliferation assays was estimated using the CellTiter $96^{\circledR}$ AQueous One Solution proliferation assay (MTS, Promega Corporation). This colorimetric method utilises conversion of the tetrazolium compound MTS (3-(4,5-dimethylthiazol-2-yl)-5-(3-carboxymethoxyphenyl)-2-(4sulfophenyl)-2H-tetrazolium) by metabolically active cells into a coloured formazan product. The product is soluble in culture media and therefore diffuses out of scaffolds and can be quantified by measuring absorbance of the culture media at $490 \mathrm{~nm}$. This is directly proportional to the number of metabolically active cells. Control culture media and hydrogels without cells were used to correct for background absorbance. Acellular and cell-laden hydrogel samples were transferred from the moulds into 48 well plates, with $200 \mu 1$ of GM per hydrogel. $60 \mu \mathrm{l}$ of MTS substrate solution was added per well and incubated for 2 hours at $37^{\circ} \mathrm{C}$ in a humidified cell culture incubator. After mixing, $100 \mu \mathrm{l}$ aliquots were transferred to 96 well plates for reading of absorbance at $490 \mathrm{~nm}$ using an Omega FluoStar plate reader. As control MTS measurements, the absorbance readings from equivalent media that had been incubated with acellular hydrogels (in triplicate) was subtracted from the measured absorbance values to yield the net MTS absorbance.

\subsection{Ultrasound setup}

The ultrasound setup consisted of a custom-built system made of modular components, similar to that previously reported.[23] The setup was installed inside a biological safety cabinet with the exception of the oscilloscope, as shown in Fig. 1a. The ultrasonic probe (Fig. 1b) consisted of a $50 \mathrm{MHz}$ single-element focused ultrasound transducer (PT-50-15-6; Toray Engineering). The focal point was calculated to be 36 and $127 \mu \mathrm{m}$ in the axial and lateral dimensions, 
respectively. Calculations were based on the measured pulse length, acoustic wavelength and focus geometry (Table S1, Fig. S3a), and using previously reported equations (Eq. S22 S25). [51] The measured depth of view was $2.1 \mathrm{~mm}$ (Fig. S3c), corresponding to the focal zone within the $-6 \mathrm{~dB}$ amplitude interval. The frequency response investigated corresponds to the $-6 \mathrm{~dB}$ amplitude interval of the transducer, ranging from $14.3-47.8 \mathrm{MHz}$, measured at the focal point on a flat reflector (Fig. S3b). Further transducer specifications are listed in Table S1. To avoid cross contamination, the transducer was equipped with a protective sleeve shown in Fig. 1a. The protective sleeve consisted of a plastic shaft with plastic wrap enclosing the lower end. The sleeve was filled with distilled water to provide an acoustic path between the transducer and the cell media, and was sterilized with $70 \%$ ethanol prior to use. Controlled and precise movement of the transducer was achieved using a 3-axis precision stage positioner, configured for $10 \mu \mathrm{m}$ resolution (LSM050A; Zaber). The stage positioner was controlled by custom-made software (The Qt company, $\mathrm{C}++$ ) with feedback on the absolute coordinates. The sample holder consisted of a 3-point leveling table, ensuring an orthogonal transducer to sample arrangement. The leveling table also featured a fitted frame to the culture well plates in order to implement an imaging coordinate system. Due to the dimensions of the transducer and sleeve, 6-well culture plates were used in this work. Because of the stage positioner range (50 $\mathrm{mm}$ ) and exposure of biological samples to non-physiological conditions, only one sample, in triplicate, was set up per culture plate. The samples were kept at room temperature for 1 hour, including the cooling down period. Ultrasound radiofrequency signals (RF) were generated and collected by a pulse receiver (5073PR; Olympus). The pulse-receiver settings for pulse repetition frequency, energy and damping were set in all cases to $1 \mathrm{kHz}, 2 \mu \mathrm{J}$ and $50 \Omega$, respectively. The gain was set to $+15 \mathrm{~dB}$ for power measurements, and $+35 \mathrm{~dB}$ for imaging. A high resolution 12-bit oscilloscope (HDO4032; LeCroy) was used to digitize and store the data, at a sampling frequency of $2.5 \mathrm{GS} / \mathrm{s}$. The digitized RF signal is the result of 160 averaged scans. Signal processing was done separately using custom-made MATLAB scripts (Mathworks). 


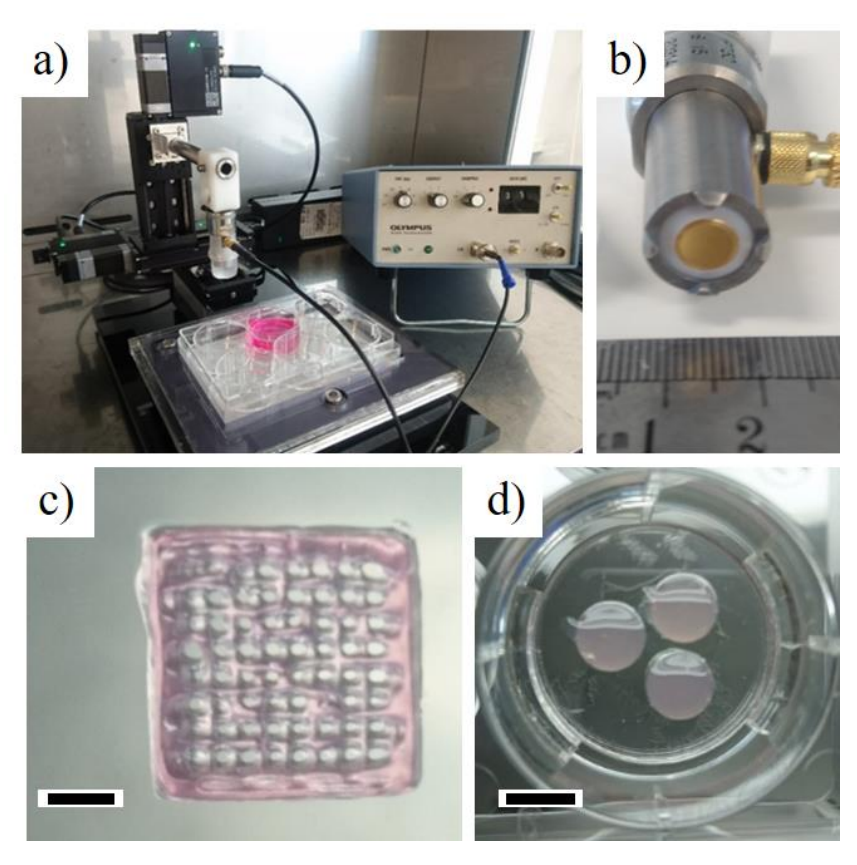

Fig. 1. a) Photograph of the setup used in this work. On display is the focused transducer fitted with a protective sleeve, a 3-axis positioning system, a 3-point levelling table, and the ultrasound pulse/receiver control unit. The oscilloscope was placed outside of the biological safety cabinet. b) Photograph of the transducer's active element. c) A photograph of the prepared printed hydrogel measured in this work. The scale bar corresponds to $250 \mu \mathrm{m}$. d) Top view photograph of a 6-well culture plate illustrating the cell-laden hydrogels measured in this work. The hydrogels were immobilised at the bottom of the well, with an acrylic frame to define the sample diameter. The scale bar corresponds to $8 \mathrm{~mm}$.

\subsection{Signal processing}

The backscattering coefficient (BSC) was calculated following the reference phantom method.[52] [53] The reference phantom was measured rather than being modelled. For the PC12 cell-laden constructs, the reference phantom had a cell density of $4.0 \times 10^{6}$ cells $/ \mathrm{ml}$, chosen arbitrarily from one of the three replicates prepared. The reference phantom procedure was repeated for each of the investigated data sets. In the case of the bioprinted hydrogel, the reference phantom consisted of the analogous cell-laden cast hydrogel. See Appendix 2 for all formulae and diagrams used for the signal processing. Briefly, the reference phantom thickness was calculated following our original approach (Fig. S1, Eq. S1, S2), which was then used to calculate the speed of sound (Eq. S3) as proposed previously.[54, 55] Attenuation measurements were done by the substitution method (Eq. S4). [55] [56] The resulting attenuated spectra was then fitted with a quadratic function within the $-6 \mathrm{~dB}$ interval, to yield 
the regression coefficients as a function of frequency (Eq. S5). For calculating the backscattering coefficient of the reference phantom (BSCR, Eq. S6), gated RF signals were converted to the frequency domain by the use of Hanning-gated Fourier transforms (FT).[57] [36, 58] All FTs were zero padded to 12502 points. The FT in amplitude shown in Fig. S3a and $\mathrm{S} 3 \mathrm{c}$ has been rescaled to its actual amplitude by a factor from dividing FT length by the number of RF points. Two gate lengths were investigated: 0.3 and $0.6 \mathrm{~mm}$, corresponding to a pulse length (PL) of 8 (8.26) and 16 (16.53) units, respectively. The PL is calculated by dividing the gate length by the transducer's axial resolution. The gate overlap was 72.4 and $83.9 \%$ for 16 and $8 \mathrm{PL}$, respectively. Based on the sampling frequency of $2.5 \mathrm{GS} / \mathrm{s}$ and the speed of sound in water, a gate length of 0.3 and $0.6 \mathrm{~mm}$ correspond to a RF segment of 504 and 1008 points, respectively. The normalised power spectra (NPS, Eq. S7) was determined using the single point attenuation correction.[59] Note that the power ratio is done between the reference sample and the reference power spectrum corresponding to the same relative distance from the gate centre or reflector to the transducer. The reflection coefficient (Eq. S9) was 0.255, corresponding to the interface between polystyrene culture plate and water. After averaging all lateral RF scans, the $\mathrm{BSC}_{\mathrm{R}}$ per gate, as a function of frequency was then calculated from the NPS, including gate length, relative distance to transducer, and a constant related to the FT gating function.[36] [58] [60] Note the relative distances between gate depth, hydrogel thickness and water path (Fig. S2, Eq. S8). For calculation of the backscattering coefficient of the sample (BSCs), the local attenuation was first computed using the spectral difference method (Eq. S10).[52] [61] [62] The BSCs per gate, per averaged RF, as a function of frequency was calculated as previously described (Eq. S11).[52] [53] Note that in this case, the power ratio is done between the sample and the RPM for each gate depth. The $\mathrm{BSC}_{\mathrm{T}}$ is the averaged BSCs for all intervening axial gates and lateral pixels (Eq. S12, S13). To extract the integrated backscattering coefficient (IBC) per gate and per averaged RF, the BSCs spectra was integrated within the $-6 \mathrm{~dB}$ interval (Eq. S14). The total IBC (IBC $)$ ) was calculated by averaging IBC for all RFs, and all gates (Eq. S15). See further details in Appendix 1 and 2 for performing the above mentioned measurements.

Size modelling was performed by converting experimental BSC into form factor units (Eq. S17), and comparing them with the modelled form factors (FFs). The FFs were modelled using the Anderson model,[63] in which cells are considered as fluid spheres. Scatter size radii was modelled from 1 to $70 \mu \mathrm{m}$, in $1 \mu \mathrm{m}$ steps. Modelling parameters related to cell properties were; speed of sound: $1523 \mathrm{~m} / \mathrm{s}$, density: $1.18 \mathrm{~g} / \mathrm{ml}$. Values were taken from the PC-3 epithelial cell 
line as indicative values [64] Before size modelling, BSC spectra were filtered by excluding those with IBC below $0.8 \times 10^{-4} \mathrm{sr} \mathrm{cm}^{-1}$. The search for the closest FF that best describes the BSC spectra was done by the minimum averaged squared difference (MASD) approach (Eq. S1618).[60] The goodness of fit between BSC and its FF given by MASD was then tested by calculating the coefficient of regression $\mathrm{R}^{2}$ (Eq. S19-21).[65] The procedure was repeated for each of the BSC spectra associated with each of the image pixels. Only modelled diameters with regression coefficients between 0.8 and 1 where chosen for consideration. Diameters associated to the excluded spectra were replaced by zeros.

\subsection{Image formation}

A summary of the signal processing steps and image formation are illustrated in Fig. 2. Upon ultrasound scanning over the cell-laden hydrogel, RF signals enclosed in the ROI were converted into the frequency domain by the use gated FTs. After laterally averaging a suitable number of FTs per gate and including corrections for power, diffraction, attenuation and geometrical considerations, the BSC and IBC per pixel could be determined. Parametric IBC images were then constructed, based on a coloured intensity index. Following image smoothing procedures, the final IBC image shown in Fig. 2 could be achieved. Smoothing procedures consisted of expanding 5 times the data array in the lateral and axial dimensions, followed by a moving average of 5 units in both dimensions. Due to the large variations of ultrasound estimates within a ROI, ultrasound images are best illustrated on a logarithmic scale. A similar procedure was done for generating images of local attenuation (not shown), cell density and scatter size. In the case of greyscale images, the envelope of the unprocessed RF signals was used to generate grey coloured intensity index. The greyscale images are presented without applying smoothing procedures.

For imaging PC12 cell-laden construct, consecutive RF were spaced by $30 \mu \mathrm{m}$, corresponding roughly to a quarter of a beamwidth (e.g. $127 \mu \mathrm{m})$. A total of 100 consecutive scans were taken, corresponding to a distance of $2.97 \mathrm{~mm}$. In the case of the bioprinted construct, RF were spaced by $60 \mu \mathrm{m}$. A total of 200 consecutive scans were taken, corresponding to $11.94 \mathrm{~mm}$. The same spacing was used between planes. A lateral RF averaging of 2 and 1 were used for a spacing of 30 and $60 \mu \mathrm{m}$, respectively. Details for performing the reference phantom measurements are provided in Appendix 1. 
An important consideration is the height and depth of the ROI within the construct. The ROI height should not exceed the transducer's depth of view, corresponding to the focal zone within $-6 \mathrm{~dB}$ amplitude interval. The ROI depth is centred at the depth of focus, and the ROI height is defined by the travel range performed on power-height measurements. Care should be taken to position the ROI at a certain offset from rigid surfaces, where acoustic interferences occur. Acoustic interferences start to decrease when the distance to reflector is greater than half of the depth of view (see Fig. S4). The presence of artefacts should be evaluated experimentally as it is an interplay of the reflector material and thickness, as well as the focal distance to the reflector.

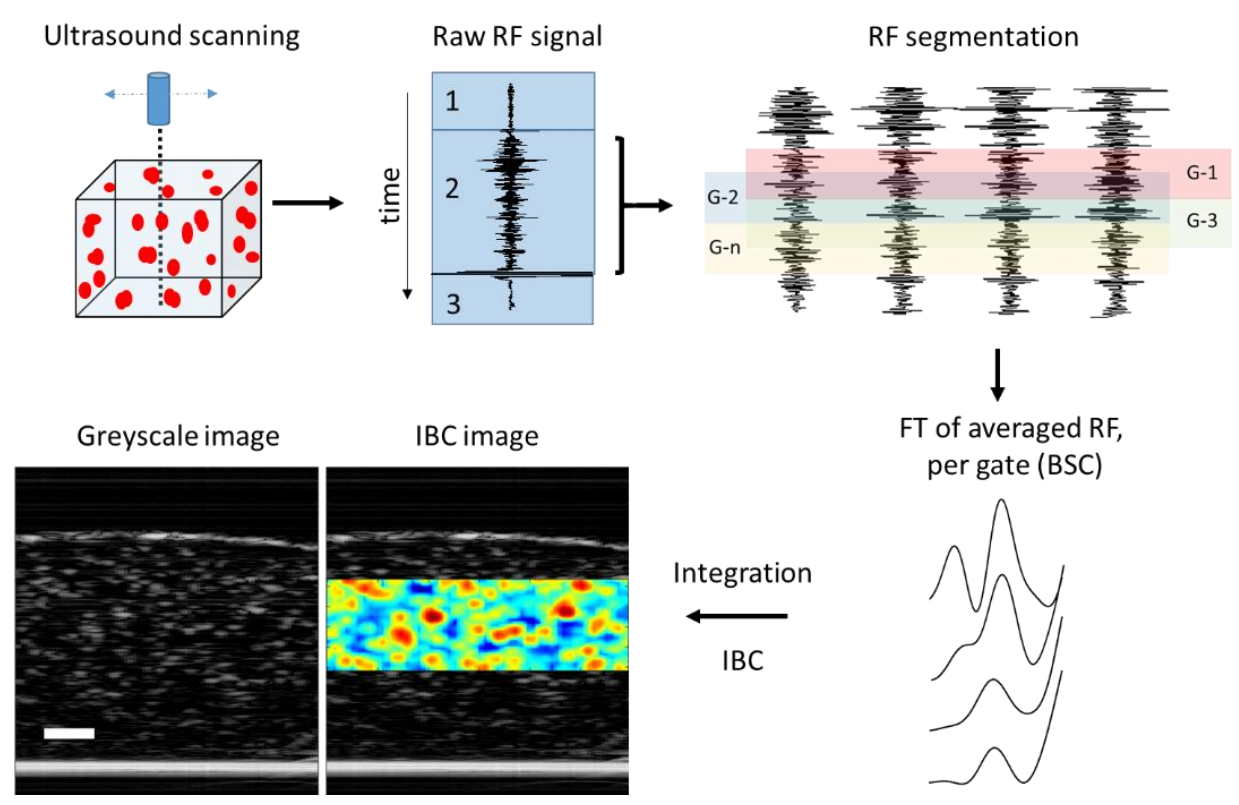

Fig. 2. Overview of the procedure for quantitative ultrasound imaging. For a given ultrasound scan over a construct with scatters (e.g. cells), a portion of the acquired radiofrequency (RF) signals (region 2) are split into overlapping segments (e.g. gates). Following the conversion of RF segments into the frequency domain, the backscattering coefficient (BSC) for each gated RF segment can be determined. The gate length and the number of laterally averaged RF segments per BSC defines the image pixel size. The numerical integration of BSC per image pixel yields the integrated backscattering coefficient (IBC). Finally, a colour-coded parametric image can be generated from the resulting IBC values. The greyscale and IBC images in display correspond to a PC12 cell-laden hydrogel of $1.0 \times 10^{6}$ cells $/ \mathrm{ml}$. The scale bar corresponds to 500 $\mu \mathrm{m}$. 


\subsection{Statistical analysis}

Values are expressed as their means \pm SD where applicable. Details on sample population are provided in each section. Linear regressions of IBC, comparison of attenuation measurements and MTS to IBC relationship were performed with OriginPro (Originlab). Linear regressions for the spectral difference method was done using the polyfitzero function of first order. Biexponential fitting of single point attenuation measurements was done using polyfitzero function of second order. The latter two were implemented in the custom-made MATALAB scripts.

\section{Results}

\subsection{Speed of sound and attenuation measurements}

The consistency of the prepared collagen hydrogels was evaluated by the measured speed of sound method as an indirect estimate of the hydrogel mechanical properties. The first consideration is the reproducibility of the cell-laden hydrogels used as the reference phantom, which was prepared with a cell density of $4.0 \times 10^{6}$ cells $/ \mathrm{ml}$. Three different reference phantoms were prepared, each corresponding to one of the calibrations investigated. The resulting values are listed in Table 1, presented together with the thickness and attenuation measurements performed on the respective reference phantom. In terms of the variation of the speed of sound across one set (e.g. set 3), the average and standard deviation for the 5 different investigated cell densities ( $\mathrm{n}=65,13 \mathrm{each}$ ) was $1485 \pm 3.5 \mathrm{~m} / \mathrm{s}$. The reference phantom thickness and fitted attenuation were calculated over all measured locations $(n=40)$. With regard to the attenuation measurements, the spectral difference method (SDM, Eq. S10) was compared with a separate set of single point measurements (Eq. S5, S6) in order to validate its application within the investigated cell densities. An example of the fitted attenuation spectra for set 3 is shown in Fig. S5, or in terms of attenuation, at centre frequency as a function of cell density shown in Fig. S6. For comparison, the attenuation determined by SDM as a function of cell density is shown in Fig S7. Note that the attenuation determined is expressed as a differential relative to the reference phantom. In order to extract a single value per sample using the SDM, following ultrasound imaging and signal processing, the local attenuation image was averaged laterally and axially to yield a final single value. In both single point and SDM measurements, the same non-linear variation is present and appears to be characteristic for the evaluated interval. 
Representation of both measurements (Fig. S8) yields a linear relationship $\left(\mathrm{R}^{2}=0.967\right)$ which validates the use of the SDM for the determination of local attenuation.

Table 1. Summary of the speed of sound, thickness and attenuation properties of the prepared reference phantoms, together with results from the IBC calibrations of PC12 cell-laden hydrogels as a function of cell density.

\begin{tabular}{|c|c|c|c|c|c|c|c|}
\hline & \multirow{2}{*}{$\begin{array}{c}\text { Speed of sound } \\
\text { RPM (m/s) }\end{array}$} & \multirow{2}{*}{$\begin{array}{l}\text { Thickness } \\
\text { RPM (mm) }\end{array}$} & \multicolumn{3}{|c|}{ Fitted attenuation (RPM) } & \multicolumn{2}{|c|}{ IBC calibration } \\
\hline & & & C1 $\left(10^{-2}\right)$ & $\mathrm{C} 2\left(10^{-2}\right)$ & $\mathbf{R}^{2}$ & Slope $\left(10^{-4}\right)$ & $\mathbf{R}^{2}$ \\
\hline Set 1 & $1472.6 \pm 1.9$ & $2.12 \pm 3.4 \times 10^{-3}$ & 3.18 & 0.27 & 0.997 & $1.699 \pm 0.058$ & 0.995 \\
\hline Set 2 & $1490.5 \pm 2.5$ & $2.35 \pm 0.10$ & 2.06 & 0.24 & 0.995 & $1.421 \pm 0.029$ & 0.998 \\
\hline Set 3 & $1484.7 \pm 2.2$ & $2.23 \pm 1.6 \times 10^{-3}$ & 4.40 & 0.25 & 0.996 & $1.091 \pm 0.021$ & 0.998 \\
\hline
\end{tabular}

\subsection{Ultrasound calibration of cell-laden hydrogels}

The relationship between backscattered ultrasound and PC12 cell density was examined in detail by performing 3 independent calibration sets. For each calibration, 5 different cell-laden hydrogels were prepared in two-fold cell density increase from $0.5-8.0 \times 10^{6}$ cells $/ \mathrm{ml}$. For each investigated cell density, 3 replicate samples were analysed, with 100 measurements on each. An example of greyscale imaging of the investigated constructs is shown in Fig. 3a, together with optical images of the same construct in Fig. 3b.

An example of BSC spectra measured on set 3 is shown in Fig. 4a, corresponding to the averaged $\mathrm{BSC}_{\mathrm{T}}$ (Eq. S12) for each cell density replica $(\mathrm{n}=100)$. The $\mathrm{BSC}_{\mathrm{T}}$ spectrum for an acellular collagen hydrogel is included as a dashed line. For ultrasound calibration purposes, a gate length of $16 \mathrm{PL}$ and lateral averaging of 100 independent scans were used. Ultrasound calibration can also be expressed in terms of IBC as a function of cell density, as shown in Fig. $4 \mathrm{~b}$ for the three independent calibrations investigated. Linear regression in the form of $y=a x$ between IBC and cell density $\left(10^{6}\right.$ cells $\left./ \mathrm{ml}\right)$ yielded the fitting slope, which can be used for the estimation of cell density from IBC measurements. The resulting fitting slopes are listed in Table 1. The final IBC to PC12 cell density relationship was $(1.404 \pm 0.031) \times 10^{-4} \mathrm{sr} \mathrm{cm}^{-1}$, expressed as the averaged slope and standard deviation. The $\mathrm{IBC}_{\mathrm{T}}$ of acellular collagen hydrogels was $1.04 \times 10^{-5} \mathrm{sr} \mathrm{cm}^{-1}$ and was not considered for $\mathrm{IBC}_{\mathrm{T}}$ calibration as a function of 
cell density. The IBC fitted slope was unaffected when including acellular hydrogels. The $\mathrm{IBC}_{\mathrm{T}}$ due to acoustic interferences was $8.69 \times 10^{-6} \mathrm{sr}^{-1}$, measured in water with the same settings and ROI location as with the hydrogels.
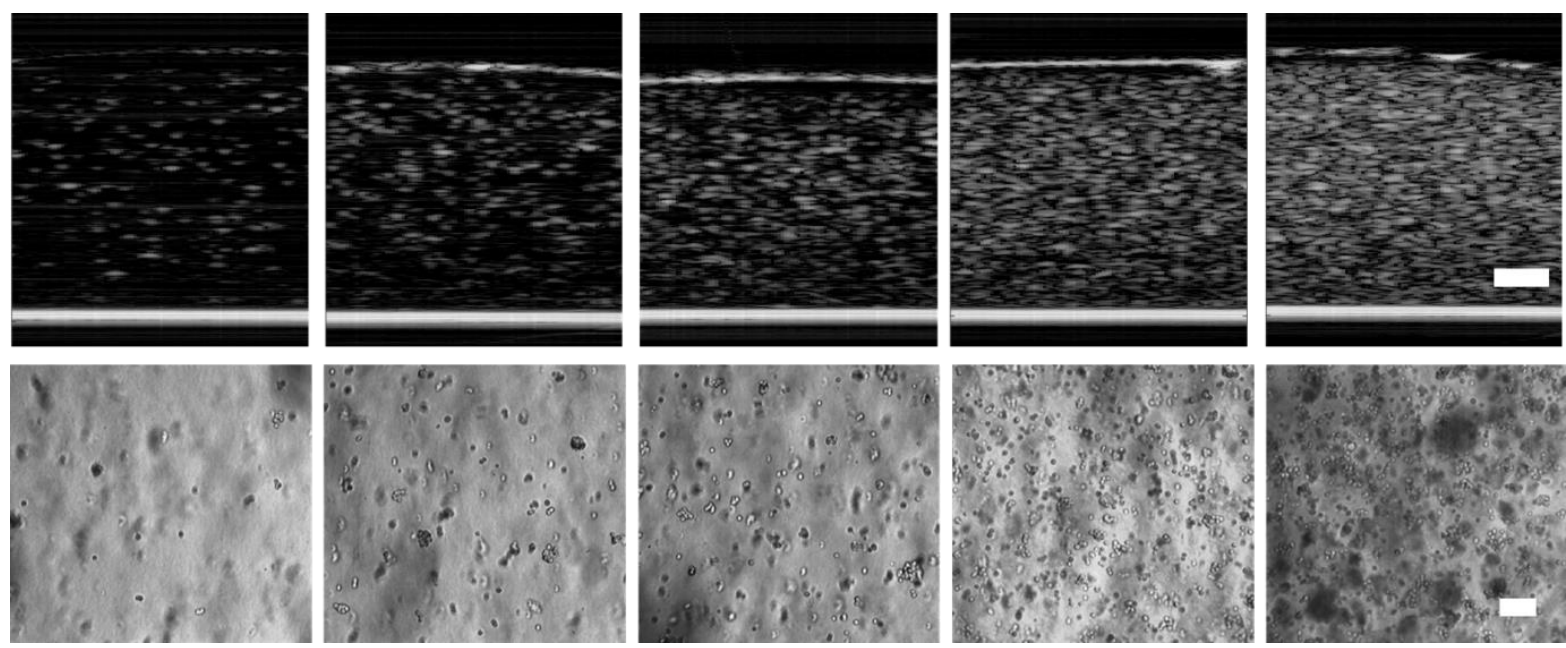

Fig 3. Top row, Representative ultrasound greyscale images of the PC 12 cell-laden hydrogels used for IBC calibration. The scale bar corresponds to $500 \mu \mathrm{m}$. Bottom row, representative optical microscopy images of the same samples. Scale bar corresponds to $100 \mu \mathrm{m}$. In both set of images, cell density increases from left to right, from $0.5-8.0 \times 10^{6}$ cells $/ \mathrm{ml}$.

a)

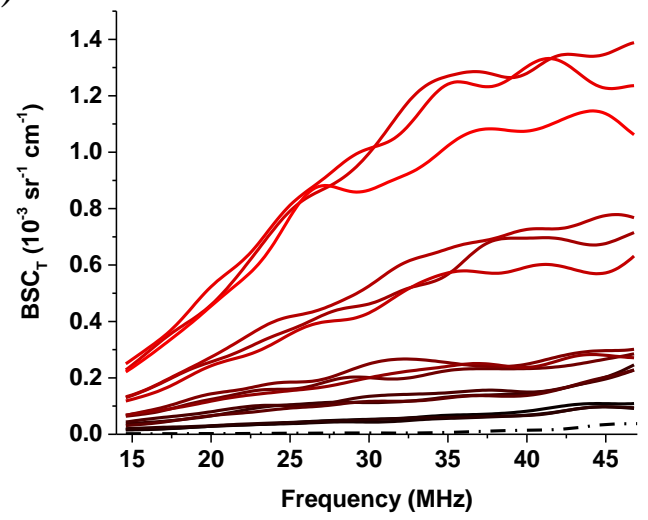

b)

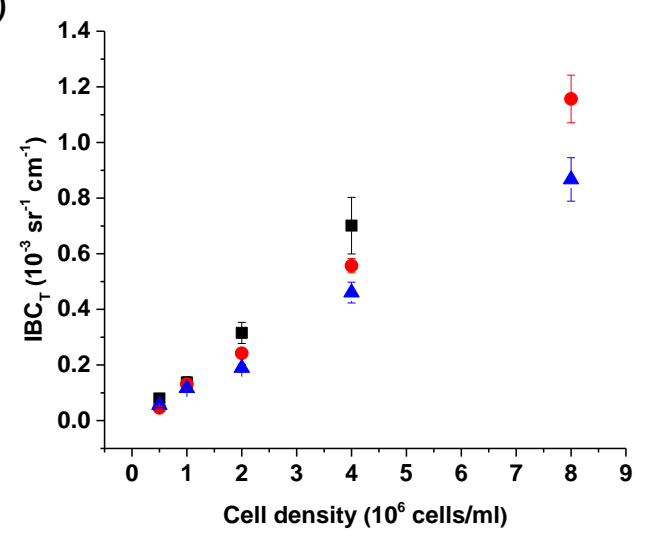

Fig. 4. a) Representative BSC spectra within the $-6 \mathrm{~dB}$ frequency interval measured on the investigated cell-laden PC12 collagen type I hydrogels, expressed as the averaged $\mathrm{BSC}_{\mathrm{T}}$ $(n=100)$ per investigated sample replica at each cell density. From bottom (black) to top (red), increasing concentration of PC12 cells from $0.5-8.0 \times 10^{6}$ cells $/ \mathrm{ml}$. BSC $\mathrm{B}_{\mathrm{T}}$ spectrum for acellular collagen hydrogel shown in dashed line. b) Averaged $\operatorname{IBC}_{\mathrm{T}}(\mathrm{n}=300)$ as a function of cell density, for each calibration set. Error bars indicating the SD for each cell density. 


\subsection{Effect of pixel size on the accuracy of IBC estimates}

Before the application of IBC slopes for estimation of the local cell density, a careful analysis of IBC as a function of pixel size was required. To carry out the study, the same data subset or region of interest (ROI) was processed by varying the pulse length (e.g. gate length) and the number of beamwidths (e.g. number of averaged lateral scans). In order to match the height of the ROI for both pulse lengths, the number of gates for the $16 \mathrm{PL}$ case was reduced to 8 and 32 for the 8 PL case. The latter yields a nearly identical ROI height and both centred on the same depth: $0.88 \mathrm{~mm}$ and $0.9 \mathrm{~mm}$ for 16 and $8 \mathrm{PL}$, respectively. The equivalent image representation of altering the pixel size is shown in Fig. S9, where it can be seen that the one processed at 8 $\mathrm{PL}$ and $0.5 \mathrm{BW}$ has the best resolution and optimum fidelity to the unprocessed raw image. No further improvement was achieved when using smaller pixel dimensions. Comparison of $\mathrm{BSC}_{\mathrm{T}}$ spectra processed with $25 \mathrm{BW}$ but with different gate length is shown in Fig. 5a, where data processed at $8 \mathrm{PL}$ appears to be smoothed with respect to the $16 \mathrm{PL}$ BSC spectrum. The same procedure was repeated for each of the investigated cell densities. Following integration of BSC to all data, the resulting 3D plot can be seen in Fig. 5b. The relative IBC error is expressed as the relative variation with respect to the largest pixel size, which is 16 PL and 25 beamwidths. To highlight, is the low relative error variation without exceeding $10 \%$ when using a pixel size of and $8 \mathrm{PL}$ and $0.5 \mathrm{BW}$. In terms of IBC error as a function of cell density, the data indicates a greater biased error for cell densities above $1.0 \times 10^{6}$ cells $/ \mathrm{ml}$. 


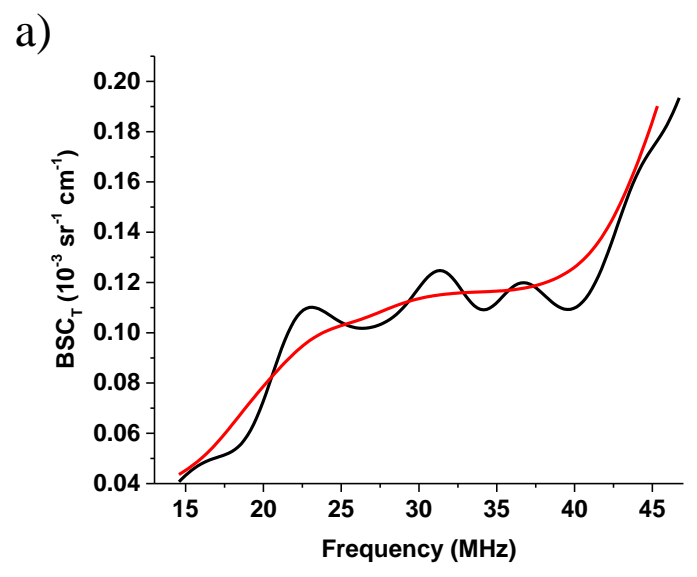

b)

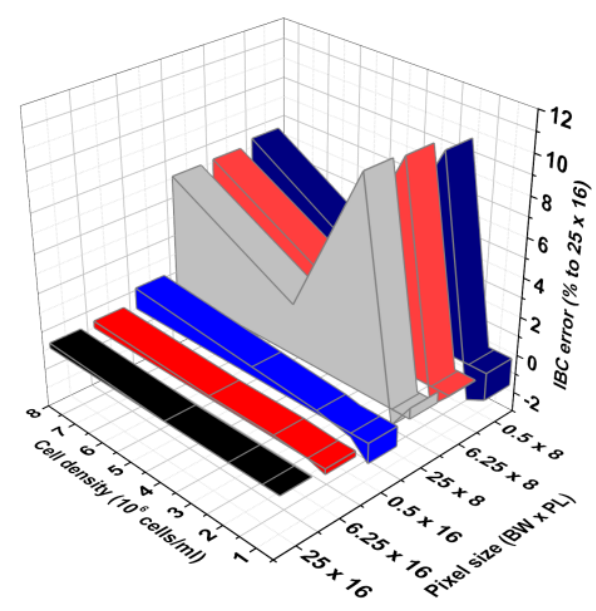

Fig. 5. a) Averaged $\mathrm{BSC}_{\mathrm{T}}$ spectra corresponding to a cell-laden hydrogel of $1.0 \times 10^{6}$ cells $/ \mathrm{ml}$, processed with a pulse length (PL) of 8 (red) and 16 (black), with the same lateral averaging of 25 beamwidths (BW). b) 3D plot of biased errors on IBC $_{\mathrm{T}}$ as a function of the cell density and pixel size, expressed as the relative $\mathrm{IBC}_{\mathrm{T}}$ error with respect to a pixel size of $25 \mathrm{BW}$ and 16 PL.

\subsection{Cell density estimation as a function of PC12 cell growth}

Once the feasibility of performing quantitative ultrasound imaging at high resolution was corroborated, the monitoring of PC12 growth in collagen hydrogels was performed. Prepared cell-laden hydrogels had an initial cell density of $1.0 \times 10^{6}$ cells $/ \mathrm{ml}$. IBC based images where transformed into local cell density images by the application of the calibrated IBC to cell density relationship. Fig. 6a shows an example of a time course of cell growth, cultured for a period of 72 hours and imaged at 24 hour intervals. The image width corresponds to a $2.97 \mathrm{~mm}$ cross-section. All colour images are represented within the same colour index interval, in the 
logarithmic scale from -1.6 to 1.2 , corresponding to a cell density interval from $0.025-15.8 \times 10^{6}$ cells $/ \mathrm{ml}$. The cell density uncertainty is given by the IBC standard deviation, which scales by $( \pm \mathrm{c} \times 0.01)$, where $\mathrm{c}$ is the cell density in $10^{6} \mathrm{cell} / \mathrm{s} / \mathrm{ml}$. The use of a coordinate system allowed the monitoring of spatiotemporal changes during cell growth over the same or closely located scan planes. For example, see the centre sections in Fig. 6a, from 24 to 72 hour intervals. For comparison, optical microscopy images of the same samples are shown in Fig. 6c. Another useful ultrasound data presentation in terms of overall cell density increase is shown in Fig. 6d. In this case, a single value of cell density per sample was determined by sampling in noncorrelated points as in the procedure for calibration (see Appendix 1), and averaging all values laterally and axially. Error bars indicate the cell density variation for the three replicates of each sample ( $n=300,100$ per replicate). Starting with 4 equivalent samples, every 24 hours a sample was removed for evaluation with the MTS assay. In Fig. 6d can also be seen the relative increase with respect to the 0 hour sample, in which the overall cell growth follows, on average, a steady $40 \%$ increase every 24 hours. Visualization of averaged $\mathrm{BSC}_{\mathrm{T}}$ spectra is also useful as a qualitative indicator of morphological cellular changes occurring over culture time. Fig 6e shows the progressive overall increase of BSC over time, where interesting spectral features can be seen. In regard to morphological changes, the emerging peak in Fig. 6e is related to the increase in scatter size (Fig. 6c). The change of slope for the 72 hours growth (top spectrum) was assigned to the onset of cell death,[37] which is supported by the observation of a population of cells shrinking and degradation into cellular debris, indicating apoptosis (Fig. 6c, 72 hour sample). 
a)
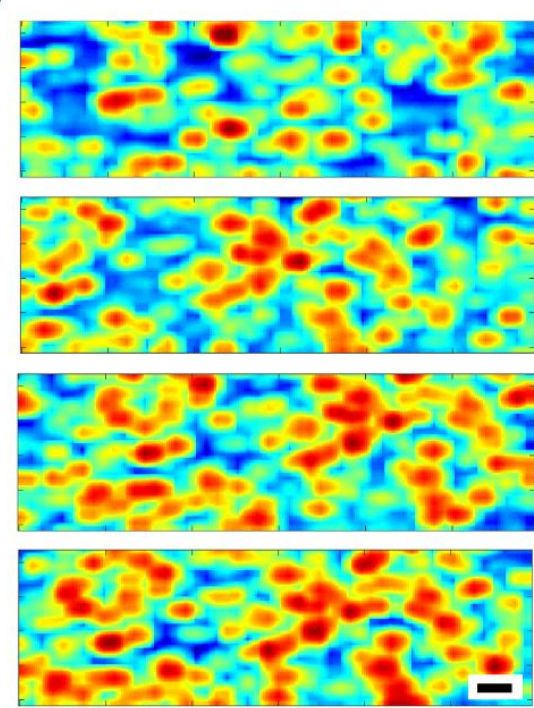

Cell density, $10^{6}$ cells $/ \mathrm{ml}$

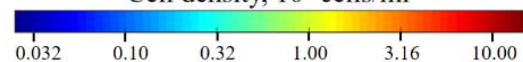

b)
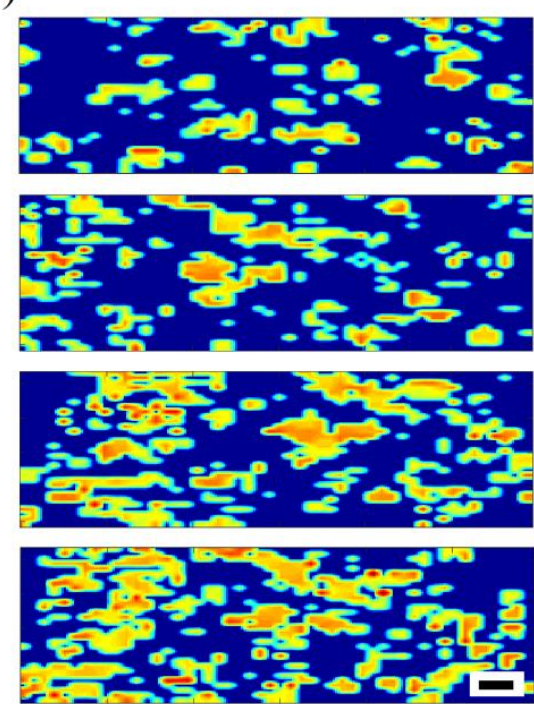

Modelled diameter, $\mu \mathrm{m}$

$\begin{array}{lllllllll}2.52 & 3.98 & 6.31 & 10.00 & 15.85 & 15.12 & 39.81 & 63.10 & 100.00\end{array}$

c)
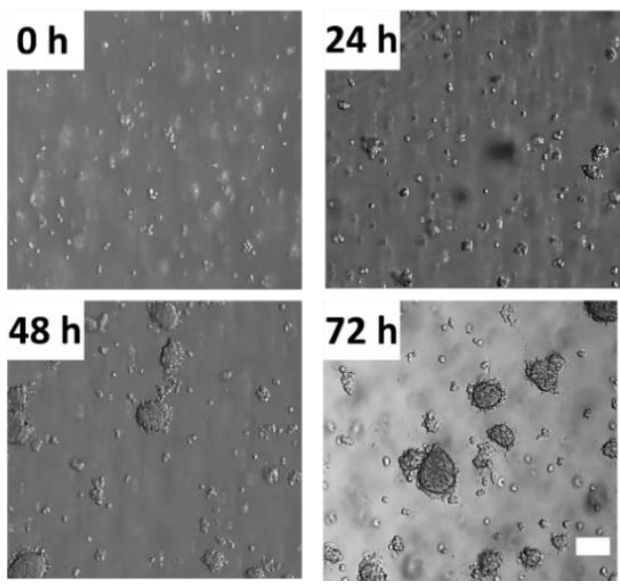

d)

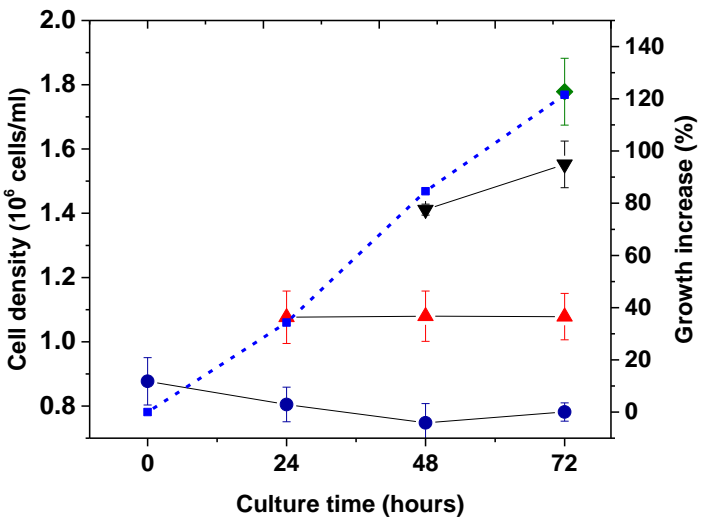

e)

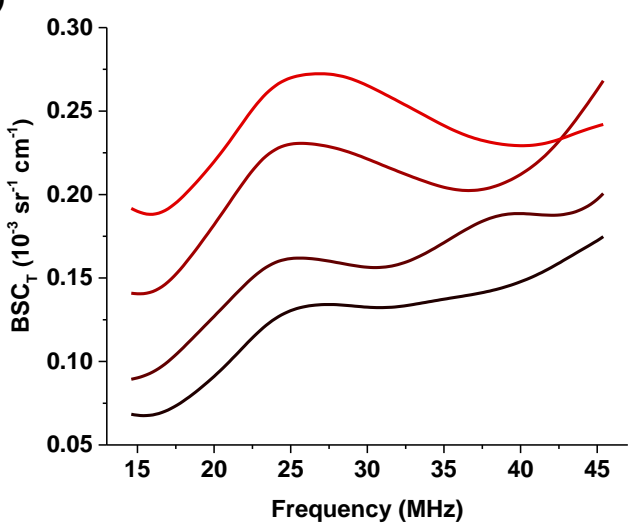

Fig. 6. a) Ultrasound cell density images of PC12 cells in collagen hydrogels as a function of culture time, from top to bottom, $0,24,48$ and $72 \mathrm{~h}$. Cell density corresponds to \pm (colour index 
$\mathrm{x} 0.01) \times 10^{6}$ cells $/ \mathrm{ml}$. b) Ultrasound images of scatter diameter determined from (a). Scatter size diameters in display are filtered for fitting coefficients $\mathrm{R}^{2}$ between 0.8 and 1 . In both images (a and b), scale bar corresponds to $200 \mu \mathrm{m}$. Images are best displayed on screen. c) Microscopy images of the same samples as in (a and b). Scale bar corresponds to $100 \mu \mathrm{m}$. d) Left axis; averaged cell density values per triplicate at $0 \mathrm{~h}$ (dots), $24 \mathrm{~h}$ (upper triangles), $48 \mathrm{~h}$ (lower triangles), $72 \mathrm{~h}$ (square). Right axis; overall increase in PC12 cell density expressed as the relative growth with respect to $0 \mathrm{~h}$ sample (dashed line). e) Spectral evolution of $\mathrm{BSC}_{\mathrm{T}}$ of PC12 laden collagen hydrogels, from 0 to 72 hours of culture period, processed with 8 PL and 0.5 BW. Spectra displayed from bottom to top corresponding to the time interval from 0 to 72 hours, respectively.

\subsection{Scatter size estimation as a function of PC12 cell growth}

Similarly as done for the relative IBC error estimation, the averaged scatter diameter (Fig. S10) was tested as a function of pixel size and culture time. The average diameter represented in Fig. S10, is the average of the individual fitted diameters for each of the image pixels, accounting only for non-zero values (see section 2.5). The use of large lateral averaging (e.g. 6.25 or $25 \mathrm{BW}$ ) followed by spectral fitting, was found to negatively affect the determination of scatter estimates, as spectral features cancelled each other. As a result, all spectra processed at wide BW yields a diameter of about 19-21 $\mu \mathrm{m}$, despite the clear increase in scatter size at extended culture times (Fig. 6c). Larger diameters, but still without an accurate representation to the actual scatter diameter was found for $0.5 \mathrm{BW}$ averaging. Small differences of scatter sizes were found when varying the PL from 16 to 8 . Based on the latter findings, scatter size information is best expressed in the form of images where the local scatter variation as a function of time can be seen (Fig. 6b). In display is the corresponding cell cluster size given by the FF that best described the BSC spectral shape, applied to each of the image pixels. The colour index is expressed in the logarithmic scale for scatter diameters from 2 to $100 \mu \mathrm{m}$, corresponding to the blue to red interval, respectively. Note the resemblance of features between cell density and scatter size, and their similarity to optical images. Some examples of scatter size determination using FF can be found in Fig. S11, corresponding to 22, 50 and 98 $\mu \mathrm{m}$. Fitting examples taken from image $6 \mathrm{~b}$ at $72 \mathrm{~h}$ of culture time. 


\subsection{MTS cell density calibration and cell growth monitoring}

Validation of the observed ultrasound results in terms of cell density estimation was performed using the MTS assay. Tested samples were the same cell-laden hydrogels used for calibration and cell growth experiments to allow for direct comparison of ultrasound and MTS estimations. The averaged net MTS absorbance values for each cell density for the three calibration datasets are shown in Fig. S12. In line with measured IBC values, the MTS follows a similar pattern in terms of the relative increase and differences between each dataset. It can be seen in Fig. S12 that the overall absorbance values follow an approximately linear trend up to $4.0 \times 10^{6}$ cells $/ \mathrm{ml}$. During MTS assays, it was noted that the hydrogels retained part of the coloured product resulting from the conversion of substrate by metabolic cell activity. Therefore, the measured absorbance values are to be considered as a proportion of the total absorbance. The loss of linearity at high cell densities for sets 2 and 3 was attributed to the often observed lack of linearity of biochemical metabolic assays at high cell densities. Variations in measured absorbance values could also be attributed to a number of factors, such as the hydrogel permeability to MTS and/or the slower cell metabolic activity due to extended exposure to nonphysiological conditions during ultrasound analysis. In order to assess the relationship between IBC and MTS, only the linear interval from $0.5-4.0 \times 10^{6}$ cells $/ \mathrm{ml}$ was considered. The relationship can be seen in Fig. S13, using the averaged values $(n=3)$ for each measurement. Linear regression (Fig. S14) in the form of $y=a x$ for the averaged MTS and IBC values for all datasets, yields a reasonable fitting coefficient $\left(R^{2}=0.956\right)$ with a slope of 2047.56. The latter slope relates MTS to IBC conversion and is only applicable to the conditions used in this work due to the proportional measurement of MTS released from the hydrogels.

Once the relationship between the MTS and ultrasound was determined using calibration curves of increasing cell number, a similar approach was applied to cell growth experiments. During MTS measurements of cell-laden hydrogels cultured over time (data not shown), it was noted that absorbance values were not consistent with the expected cell density from ultrasound measurements. Similar as with MTS calibration, the latter was attributed to the slower cell metabolic activity caused by keeping the cells under non-physiological conditions during ultrasound measurements. To overcome this issue, MTS monitoring of cell number as a function of culture time was done on separate samples prepared in parallel, under the same conditions, as those used for ultrasound measurements. The measured MTS values of this dataset were transformed into IBC, followed by cell density calculations using the conversion 
slopes determined in sections 3.2 and 3.6. The predicted ultrasound cell density estimates (Fig. $6 \mathrm{~d}$ ), were normalized with respect to the 0 hour culture time, in order to allow comparison between these datasets. A comparison of cell growth between MTS and ultrasound measurements is illustrated in Fig. 7, with close agreement between the two.

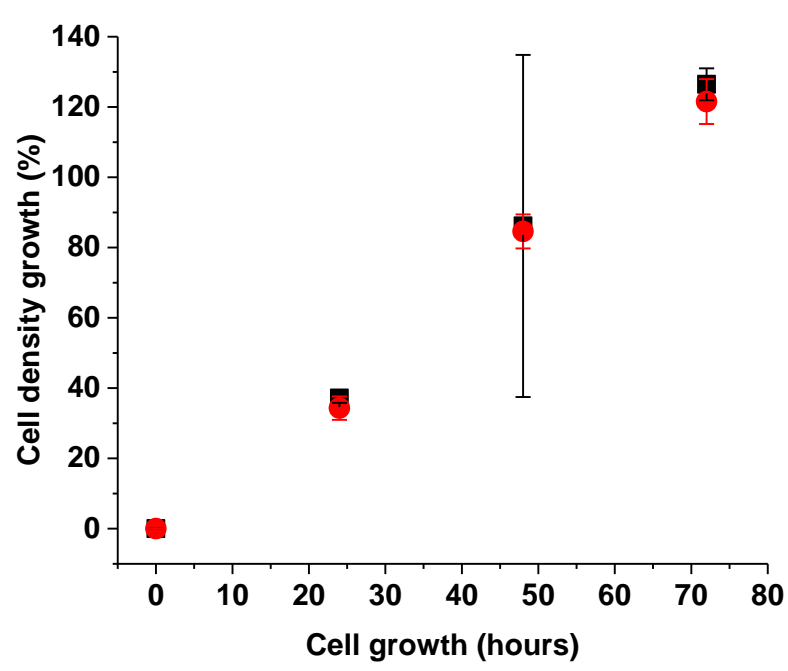

Fig. 7. Comparison between MTS (squares, black) and ultrasound (circles, red) data in relation to the relative cell growth as a function of culture time, normalised to time zero hours for comparison. Error bars indicate the standard deviation for each measurement.

\subsection{Application of QUI to bioprinted constructs.}

Following the validation of QUI to monitor cell-laden hydrogels at high resolution, we also tested its application to a 3D bioprinted hydrogel. A photograph of the measured sample is shown in Fig. 1c. A similar signal processing procedure was applied in this case. The average speed of sound determined for the reference sample was $1596.8 \pm 0.6 \mathrm{~m} / \mathrm{s} \quad(\mathrm{n}=13)$. The measured thickness was $2.78 \pm 2.56 \times 10^{-3} \mathrm{~mm}(\mathrm{n}=40)$. The fitted attenuation coefficients measured on the cast reference phantom $(n=40)$ were, $\mathrm{c} 1=0.032 \pm 1.15 \times 10^{-3}$ and $\mathrm{c} 2=1.3 \times 10^{-}$ ${ }^{3} \pm 2.16 \times 10^{-4}$. The averaged $\mathrm{R}^{2}$ and standard deviation of the fitted attenuation spectra was 0.99 $\pm 9.90 \times 10^{-4}$. For the measurement of the backscattering coefficient of the reference sample, $\mathrm{BSC}_{\mathrm{R}}$, the focus was placed $1 \mathrm{~mm}$ below the reference phantom surface, and the depth interval was extended to $1.5 \mathrm{~mm}$ instead of $0.9 \mathrm{~mm}$. The ROI height was increased in order to enclose the whole bioprinted construct within the ROI. During QUI acquisition, in order to centre the ROI starting from the bottom of the culture plate, the focus was placed $0.7 \mathrm{~mm}$ inside the 
construct instead of $1 \mathrm{~mm}$ as done in the reference phantom. Following signal processing and image formation, the resulting QUI images of the bioprinted construct can be seen in Fig. 8, corresponding to a section of $11.94 \mathrm{~mm}$ in width and $0.48 \mathrm{~mm}$ along the construct. Note that the images are expressed in an arbitrary scale of cell density relative to PC12 cells, and this may differ from HDF cells. From the visualization of images in Fig. 8, an overall uniform distribution of the colour index corresponding to $1.0 \times 10^{6}$ cells $/ \mathrm{ml}$ can be seen, with the presence of scattered cell aggregates of high cell density. The cell density profile per scan plane as a function of plane offset can be seen in Fig. 9. The differences in cell density between scan planes are attributed to the number and size of the cell aggregates. Averaging of cell densities per scan plane was performed by manually selecting the contour of the bioprinted construct, as shown in Fig. S15. The averaged cell density corresponds to the average of all intensity pixels enclosed within the defined mask. The procedure was repeated in triplicate for each scan plane.

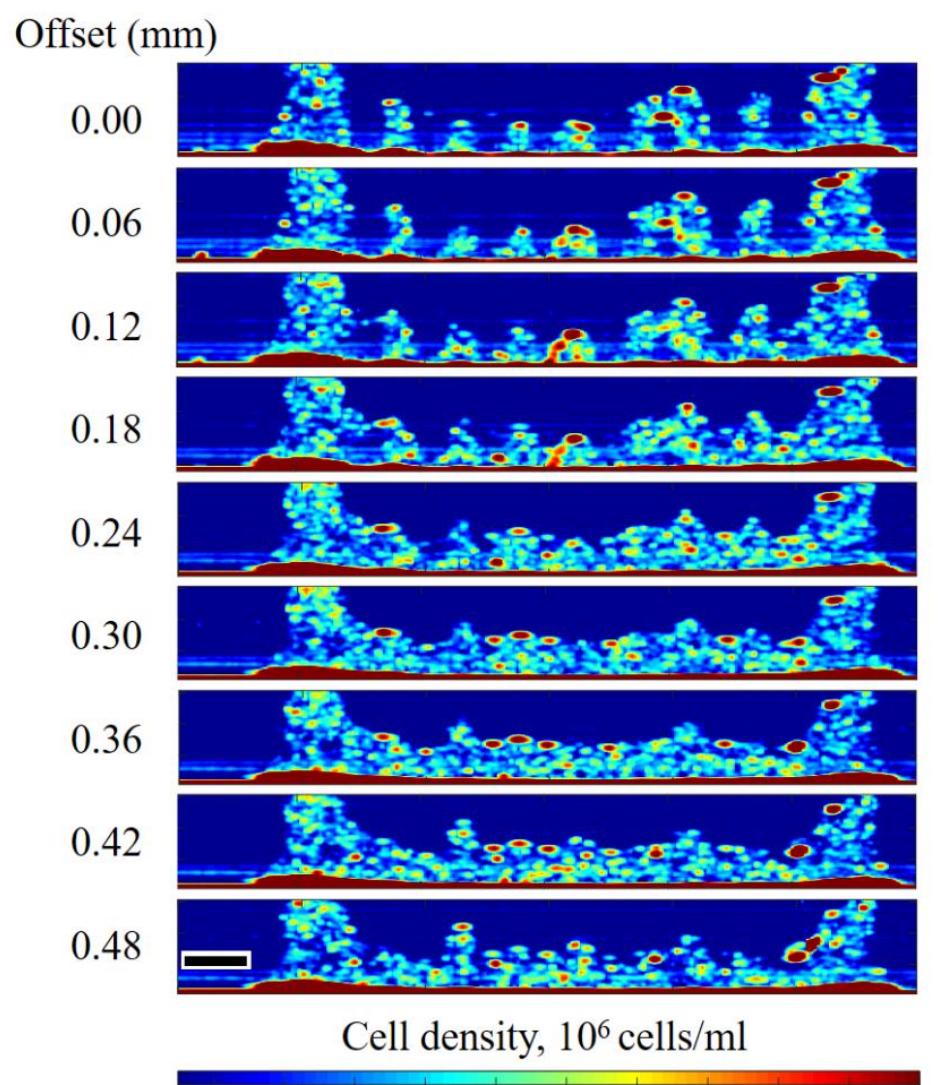

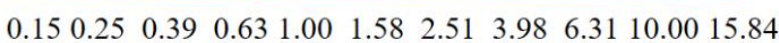

Fig. 8. Sequence of images over a 3D printed GelMA hydrogel with HDFs cells. The images are displayed in an arbitrary interval of cell density, corresponding to a cross-section of 11.94 $\mathrm{mm}$ in width, covering a distance of $0.48 \mathrm{~mm}$ along the scaffold. The scale bar corresponds to $1 \mathrm{~mm}$. 


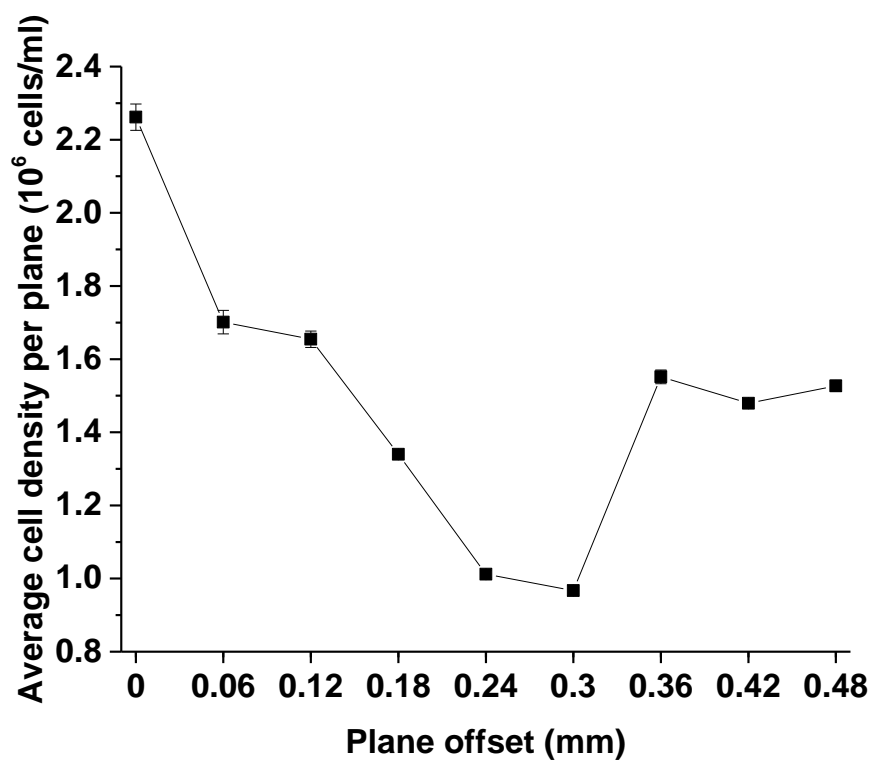

Fig. 9. Averaged cell density per plane, represented as a function of plane offset relative to the first scan plane. Error bars indicate the standard deviation from manually selecting the bioprinted contour by freehand selection. Data points interconnected with a line as an eye guide.

\section{Discussion}

Efforts towards functional tissue engineered constructs require new milestones in biology and polymer science, but also requires the implementation of new characterisation tools capable of assessing their development. The goal of this study was to expand on the capabilities and limitations of ultrasound for the interrogation of cell-laden hydrogels of reduced dimensions. In particular, we investigated the validation of ultrasound for cell density estimation, revisiting the trade-off between image resolution and accuracy, monitoring changes during cell growth, as well as the application of QUI to bio-printed structures.

The use of RPM requires that the reference sample must have the same speed of sound as the test samples, in addition to being measured at the same temperature. To avoid fluctuations, all samples were measured at room temperature. The small variation in speed of sound across the samples used for ultrasound calibration corroborates the consistency of the prepared collagen hydrogels. For instance, samples prepared for set 3 had a standard deviation of only $3.5 \mathrm{~m} / \mathrm{s}$. Some differences in the speed of sound were found between the reference samples, and to a larger extent for the sample corresponding to set 1 (Table 1). The latter may be attributed to 
small differences in the concentration of the hydrogel precursor solution and / or crosslinking conditions. The use of the spectral difference method (SDM) was confirmed to be applicable within the cell densities investigated, after comparison with attenuation data measured by the substitution method. The use of a pixel based attenuation compensation approach is of relevance since it can generate a local attenuation map of the region of interest. This could be beneficial for other studies monitoring, for example, cartilage development. [24] [34]

The ultrasound intensity, IBC, was calibrated with respect to increasing densities of PC12 cells. The cell density interval was chosen to be within the typical working range for cell-laden hydrogels. Ultrasound greyscale images and optical images (Fig. 3) corroborated, qualitatively, the increasing cell density of the prepared cell-laden hydrogels. The contribution of acoustic interferences was minimal in PC12 cell samples, since the focal point was placed $1 \mathrm{~mm}$ below the hydrogel surface, of about $2.2 \mathrm{~mm}$ in thickness. The size of the ROI was $0.9 \mathrm{~mm}$ and 0.88 $\mathrm{mm}$ for data processed at 8 and $16 \mathrm{PL}$ respectively. Interference echoes can be partially seen on the image corresponding to the lowest cell density, $0.5 \times 10^{6}$ cells $/ \mathrm{ml}$. The artefacts introduced by interference echoes were considered negligible relative to the scattering properties of the cells and no further considerations were made. In order to establish the relationship between IBC and cell density, three independent calibrations were performed (Fig. 4b). In all cases, an excellent linear correlation was achieved $\left(\mathrm{R}^{2}>0.99\right)$, although the relative intensity was slightly different for each calibration. The oscillations of $\mathrm{IBC}_{\mathrm{T}}$ for the same cell density across calibrations was attributed to small variations of the initial cell stock solutions. Due to the potential variations in the actual cell densities, the final IBC to PC12 cell density relationship is the averaged linear regression slope for the 3 independent datasets (Table 1), resulting in the relation of $\mathrm{IBC}=(1.404 \pm 0.031) \times 10^{-4} \mathrm{X}$, where $\mathrm{X}$ is cell density expressed in $10^{6}$ cells $/ \mathrm{ml}$. Acellular hydrogels were not included in the IBC calibration. Based on the calibration, acellular hydrogels would return a cell density of $7.40 \times 10^{4}$ cells $/ \mathrm{ml}$, which is negligible to the contribution of cellular hydrogels. A similar IBC for acellular collagen hydrogels has been previously reported for a comparable collagen density and crosslinking temperature.[35] The scattering properties of collagen are related to the microstructure of collagen fibres. The application of the RPM to each of the prepared collagen batches in our work compensates for any difference in the collagen microstructure. Comparison of the IBC linear regression equation to that of a previous work[36] is reasonably similar despite being a different cell line and using a different signal processing approach. Backscattering intensity is 
ultimately dependent on the acoustic impedance (density and speed of sound) mismatch between the sound propagating material and the scatter (e.g. cell).

The validity of IBC for cell density estimation was tested against the commonly used MTS assay. While MTS and other related biochemical typically yield high linear regression estimates when applied to 2D samples, application of the technique to 3D cell-laden hydrogels can decrease the precision and accuracy of cell density estimations. For example, the measured net absorbance is a relative measure only, as much of the coloured product of the MTS assay remained trapped within the hydrogel. In contrast, ultrasound gives an IBC intensity which is linearly proportional to all scattering events occurring within the interrogated volume of the construct.

Once the use of IBC to extract cell density estimates via calibration was corroborated, the image resolution as a function of pixel size was revisited. The trade-off between accuracy and image resolution has been widely discussed. [36],[46, 66],[67],[68] It has been established that in order to improve accuracy, ultrasound estimates should be extracted from a large spatial averaging of RF signals. For instance, the minimum recommended pixel dimensions should be $5 \mathrm{BW}$ wide, and $10 \mathrm{PL}$ long in order to have estimates below $10 \%$ error.[66] Such pixel size dimensions are impractical for generating finely detailed parametric maps of small biological constructs. The need for large spatial averaging implies that data processed with large axial and lateral averaging does not necessarily have to be equal to the average of pixels processed with smaller dimensions. In our case, in order to assess the relative IBC increase as a function of pixel size, the same image section was processed by varying the lateral and axial pixel dimensions. The relative error increase was normalized with respect to the data processed with the largest possible pixel size, (16 PL and $25 \mathrm{BW}$ ), in line with the general consensus. The results shown in Fig. 5 indicate a much reduced error increase in comparison with other reports, around the $10 \%$ mark when using a pixel as small as $8 \mathrm{PL}$ and $0.5 \mathrm{BW}$. The latter pixel dimensions were chosen for processing cell density (Fig. 6a) and scatter images (Fig. 6b), owing to its optimum fidelity to raw images (Fig. S9).

The scope of this work was not to question other observations on the effect of spatial averaging, but it is noted that the use of different signal processing procedures, and or the use of different assumptions to express the relative error increase can lead to different conclusions. For instance, in our case we have used the local attenuation compensation algorithm implemented on the RPM. The reference phantom was measured, instead of being modelled. The frequency 
interval was larger and of higher frequency than the reported by Oelze,[66] and the data was recorded with a 12-bit resolution oscilloscope. We also opted for calculating biased errors as a function of IBC, and not as a function of modelled estimates. Methods using the modelling approach first extract the scatter diameter, which is then used to extract the theoretical scatter density. While the use of spectral modelling is a straight forward approach which does not require calibration, inaccurate determination of scatter size can lead to strong discrepancies of scatter density as they are related by the power of 6.[46] In another study, similar to our case but without using the RPM and local attenuation, cell density values were converted from the IBC calibration and used as the evaluation parameter. [36] The effect of pixel size was then compared between the estimated and the expected cell density from the prepared hydrogels. As shown in Fig. 4b, there can be differences in IBC values for a given cell density due to experimental errors in the preparation of the cell laden hydrogels. When converting IBC values into cell density, those differences reveal that the constructs have slightly different concentrations. Computation of cell density variation based on the assumption that true cell density is exactly as intended, can lead to different biased error profiles. Since different authors use different approaches and interpretations, the relative error increase should be evaluated with respect to the well stabilised concept of large lateral and axial averaging.

In the case of measuring scatter diameter as a function of culture time, the effect of pixel size and its impact on the scatter diameter was also evaluated (Fig. S10). It was found that large spatial averaging was found not to accurately represent the actual scatter diameters, hence supporting the use of IBC calibration and scatter size modelling separately. Similarly, averaging of individual scatter diameters processed at $0.5 \mathrm{BW}$ and either 16 PL or 8 PL was not found to represent actual scatter diameters, since the averaged diameter only increases by about $4 \mu \mathrm{m}$ from 0 to $72 \mathrm{~h}$ of culture time. On the other hand, parametric scatter size maps follow in close relationship to the increase of cell cluster size as seen by microscopy as a function of culture time. Note that although microscopy and ultrasound have different image perspectives, they are comparable on the horizontal plane. PC12 cells have a diameter of about $10 \mu \mathrm{m}$, but this particular cell line tends to form clusters of 2-3 cells at cell seeding. This is consistent with the colour index seen in the scatter size map at $0 \mathrm{~h}$ culture time, where sizes of 15 to $25 \mu \mathrm{m}$ are predominant. As the culture time is extended, an increase of cluster size can be seen by microscopy. This is consistent with scatter-size maps, with an increase in colour index corresponding to $39 \mu \mathrm{m}$ and above. 
Given the increasing momentum of bioprinted structures as more efficient 3D models for tissue engineering, it was of interest to test the feasibility of using QUI on a bioprinted sample. Although we have proven the possibility to use QUI at high resolution (e.g. 0.5 BW and 8 PL), it was unclear whether ultrasound could resolve the fine features present in printed hydrogels. As evident in the resulting images (Fig. 8), ultrasound is in fact capable of recreating with good fidelity the features seen on its photograph counterpart (Fig. 1c). In terms of quantitative information, the images in Fig. 8 were displayed using an arbitrary cell density interval since there was no available IBC calibration for the cell line used. Although the cell density values are indicative, it does show the possibility of performing a quantitative analysis, in the form of cell density maps, or as the averaged cell density per scan plane. This can be useful for the optimization of bioprinting parameters or for monitoring the spatiotemporal evolution of cells as a function of the construct's properties. A point to note is the image acquisition time. The image cross-sections presented in Fig. 8 contains 200 scans per plane spaced by $60 \mu \mathrm{m}$, which was measured within 300 seconds. Provided that the sample is smaller than the transducer's depth of view (e.g. $2.1 \mathrm{~mm}$ ), image acquisition only depends on the lateral travel distance, and RF spacing. This translates into an image acquisition time of 1.5 seconds per RF including the movement of the stage positioner. This is in contrast to techniques based on optical focusing. When considering the horizontal plane, microscopy has a wider field of view compared to ultrasound which is limited by the transducer's properties. The advantage of ultrasound is the capability to generate 2D images on the vertical plane, since it does not require z-stack procedures. Thus, acquisition time is greatly reduced when imaging millimetre scale constructs when compared to optic-based techniques, if feasible at all due to thickness limitations.

The example presented in Fig. 8 anticipates special considerations to be made when imaging bioprinted constructs. Because of the presence of bodies of water within the scanned section, parametric estimates have to be extracted by free-hand selection over specific regions, instead of averaging all image pixels. Measurements of thin bioprinted constructs can also be problematic due to acoustic interferences (Fig. S4). In the example shown in Fig. 8, the focus was deliberately positioned within the interference region, with the aim of centring the ROI so that the whole construct thickness could be processed by QUI. Interference echoes are clearly seen as horizontal lines covering the whole image. Presence of echoes can interfere with the interpretation of quantitative images and derived estimates when measuring samples of low scattering properties. Insertion of high attenuation pads below the sample, or use of transducers with reduced depth of view can help to minimize the presence of interference echoes. 
One last challenging situation for bioprinted constructs and cellular hydrogels in general, is related to the hydrogel or matrix degradation or transformation. In the cases presented in this work, cells do not interact with the hydrogels, hence, the hydrogel maintained their initial structure over time. This condition allowed the implementation of the RFM. For systems where cells interact with hydrogels, for instance, where cells cause contraction of hydrogels,[69] matrix mineralization, [39] or the change of hydrogel porosity,[70] the physical properties of the hydrogel can be altered over time. This can induce changes in the scattering properties and speed of sound of the construct, which are not compensated by the RFM. This would limit the use of the RPM, and the single point attenuation compensation approach should be used. The benefit of the RPM is that it enables a pixel passed attenuation compensation, in addition to simplifying QUI acquisition procedures. The use of single point attenuation measurements assumes that the distribution of scatters is homogeneous along the acoustic path. For heterogeneous samples, or patterned constructs such as bioprinted hydrogels, the acoustic attenuation measured through the sample is not necessarily the same along the whole acoustic path. This can induce biased errors when determining the BSC. Consequently, the use of single point attenuation measurements in heterogeneous or patterned constructs can affect the accuracy as well as acquisition time. The applicability of the RPM in evolving biological constructs in terms of the hydrogel matrix should be investigated in more detail in future studies.

\section{Conclusions}

Application of QUI towards characterization of hydrogels containing living cells has been demonstrated. Here we show that combining the reference phantom method together with a local attenuation compensation function results in low biased errors when imaging at high resolution. High resolution imaging allowed the monitoring of cell growth as a function of cell number and cluster size over time. The calculated ultrasound cell density estimates were validated against a traditional metabolic assay for cell number estimation. In light of the capabilities of ultrasound to measure thin constructs, we also explored the feasibility for its application to bioprinted constructs. Finally, we also discussed some of the limitations and possibilities of the technique to monitor the development of tissue engineered constructs. 


\section{Acknowledgments}

This work has been supported by the Australian Research Council Centre of Excellence Scheme (Project Number CE 140100012). The authors would like to thank the Australian National Fabrication Facility (ANFF) Materials Node for the equipment use during this study.

\section{Disclosures}

The authors declare no conflicts of interest.

\section{References}

[1] S.V. Murphy, A. Atala, 3D bioprinting of tissues and organs, Nat Biotechnol 32(8) (2014) 773-85.

[2] C. Di Bella, S. Duchi, C.D. O'Connell, R. Blanchard, C. Augustine, Z. Yue, F. Thompson, C. Richards, S. Beirne, C. Onofrillo, S.H. Bauquier, S.D. Ryan, P. Pivonka, G.G. Wallace, P.F. Choong, In situ handheld three-dimensional bioprinting for cartilage regeneration, J Tissue Eng Regen Med 12(3) (2018) 611621.

[3] S. van Kogelenberg, Z. Yue, J.N. Dinoro, C.S. Baker, G.G. Wallace, Three-Dimensional Printing and Cell Therapy for Wound Repair, Adv Wound Care (New Rochelle) 7(5) (2018) 145-155.

[4] J.L. Bourke, A.F. Quigley, S. Duchi, C.D. O'Connell, J.M. Crook, G.G. Wallace, M.J. Cook, R.M.I. Kapsa, Three-dimensional neural cultures produce networks that mimic native brain activity, J Tissue Eng Regen Med 12(2) (2018) 490-493.

[5] R.F. Canadas, T. Ren, A. Tocchio, A.P. Marques, J.M. Oliveira, R.L. Reis, U. Demirci, Tunable anisotropic networks for 3-D oriented neural tissue models, Biomaterials 181 (2018) 402-414.

[6] A.K. Miri, A. Khalilpour, B. Cecen, S. Maharjan, S.R. Shin, A. Khademhosseini, Multiscale bioprinting of vascularized models, Biomaterials (2018).

[7] S.Y. Nam, L.M. Ricles, L.J. Suggs, S.Y. Emelianov, Imaging strategies for tissue engineering applications, Tissue Eng Part B Rev 21(1) (2015) 88-102.

[8] A.A. Appel, M.A. Anastasio, J.C. Larson, E.M. Brey, Imaging challenges in biomaterials and tissue engineering, Biomaterials 34(28) (2013) 6615-30.

[9] J.M. Mansour, Z. Lee, J.F. Welter, Nondestructive Techniques to Evaluate the Characteristics and Development of Engineered Cartilage, Ann Biomed Eng 44(3) (2016) 733-49.

[10] I. Georgakoudi, W.L. Rice, M. Hronik-Tupaj, D.L. Kaplan, Optical spectroscopy and imaging for the noninvasive evaluation of engineered tissues, Tissue Eng Part B Rev 14(4) (2008) 321-40.

[11] T. Yu, Y. Qi, H. Gong, Q. Luo, D. Zhu, Optical clearing for multiscale biological tissues, J Biophotonics 11(2) (2018).

[12] A. Boskey, N. Pleshko Camacho, FT-IR imaging of native and tissue-engineered bone and cartilage, Biomaterials 28(15) (2007) 2465-78.

[13] X. Bi, X. Yang, M.P. Bostrom, N.P. Camacho, Fourier transform infrared imaging spectroscopy investigations in the pathogenesis and repair of cartilage, Biochim Biophys Acta 1758(7) (2006) 93441.

[14] D. Baykal, O. Irrechukwu, P.C. Lin, K. Fritton, R.G. Spencer, N. Pleshko, Nondestructive assessment of engineered cartilage constructs using near-infrared spectroscopy, Appl Spectrosc 64(10) (2010) $1160-6$.

[15] K.J.I. Ember, M.A. Hoeve, S.L. McAughtrie, M.S. Bergholt, B.J. Dwyer, M.M. Stevens, K. Faulds, S.J. Forbes, C.J. Campbell, Raman spectroscopy and regenerative medicine: a review, NPJ Regen Med 2 (2017) 12. 
[16] C.M. Perlaki, Q. Liu, M. Lim, Raman Spectroscopy Based Techniques in Tissue Engineering -An Overview, Applied Spectroscopy Reviews 49(7) (2014) 513-532.

[17] C. Kallepitis, M.S. Bergholt, M.M. Mazo, V. Leonardo, S.C. Skaalure, S.A. Maynard, M.M. Stevens, Quantitative volumetric Raman imaging of three dimensional cell cultures, Nat Commun 8 (2017) 14843.

[18] D. Dalecki, D.C. Hocking, Ultrasound technologies for biomaterials fabrication and imaging, Ann Biomed Eng 43(3) (2015) 747-61.

[19] C.X. Deng, X. Hong, J.P. Stegemann, Ultrasound Imaging Techniques for Spatiotemporal Characterization of Composition, Microstructure, and Mechanical Properties in Tissue Engineering, Tissue Eng Part B Rev 22(4) (2016) 311-21.

[20] M.L. Oelze, J. Mamou, Review of Quantitative Ultrasound: Envelope Statistics and Backscatter Coefficient Imaging and Contributions to Diagnostic Ultrasound, IEEE Trans Ultrason Ferroelectr Freq Control 63(2) (2016) 336-51.

[21] K. Kim, W.R. Wagner, Non-invasive and Non-destructive Characterization of Tissue Engineered Constructs Using Ultrasound Imaging Technologies: A Review, Ann Biomed Eng 44(3) (2016) 621-35.

[22] J.M. Walker, A.M. Myers, M.D. Schluchter, V.M. Goldberg, A.I. Caplan, J.A. Berilla, J.M. Mansour, J.F. Welter, Nondestructive evaluation of hydrogel mechanical properties using ultrasound, Ann Biomed Eng 39(10) (2011) 2521-30.

[23] A. Ruland, X. Chen, A. Khansari, C.D. Fay, S. Gambhir, Z. Yue, G.G. Wallace, A contactless approach for monitoring the mechanical properties of swollen hydrogels, Soft Matter (2018).

[24] M.A. Rice, K.R. Waters, K.S. Anseth, Ultrasound monitoring of cartilaginous matrix evolution in degradable PEG hydrogels, Acta Biomater 5(1) (2009) 152-61.

[25] X. Cai, Y.S. Zhang, Y. Xia, L.V. Wang, Photoacoustic Microscopy in Tissue Engineering, Mater Today (Kidlington) 16(3) (2013) 67-77.

[26] Y.S. Zhang, L.V. Wang, Y. Xia, Seeing Through the Surface: Non-invasive Characterization of Biomaterial-Tissue Interactions Using Photoacoustic Microscopy, Ann Biomed Eng 44(3) (2016) 64966.

[27] Y. Zhang, X. Cai, Y. Wang, C. Zhang, L. Li, S.W. Choi, L.V. Wang, Y. Xia, Noninvasive photoacoustic microscopy of living cells in two and three dimensions through enhancement by a metabolite dye, Angew Chem Int Ed Engl 50(32) (2011) 7359-63.

[28] J. Weber, P.C. Beard, S.E. Bohndiek, Contrast agents for molecular photoacoustic imaging, Nat Methods 13(8) (2016) 639-50.

[29] D.Y. Santiesteban, K. Kubelick, K.S. Dhada, D. Dumani, L. Suggs, S. Emelianov, Monitoring/Imaging and Regenerative Agents for Enhancing Tissue Engineering Characterization and Therapies, Ann Biomed Eng 44(3) (2016) 750-72.

[30] L.V. Wang, S. Hu, Photoacoustic tomography: in vivo imaging from organelles to organs, Science 335(6075) (2012) 1458-62.

[31] X. Hong, R.T. Annamalai, T.S. Kemerer, C.X. Deng, J.P. Stegemann, Multimode ultrasound viscoelastography for three-dimensional interrogation of microscale mechanical properties in heterogeneous biomaterials, Biomaterials 178 (2018) 11-22.

[32] P.L. Kuo, C.C. Charng, P.C. Wu, P.C. Li, Shear-wave elasticity measurements of three-dimensional cell cultures for mechanobiology, J Cell Sci 130(1) (2017) 292-302.

[33] W. Kim, V.L. Ferguson, M. Borden, C.P. Neu, Application of Elastography for the Noninvasive Assessment of Biomechanics in Engineered Biomaterials and Tissues, Ann Biomed Eng 44(3) (2016) 705-24.

[34] B.Z. Fite, M. Decaris, Y. Sun, Y. Sun, A. Lam, C.K. Ho, J.K. Leach, L. Marcu, Noninvasive multimodal evaluation of bioengineered cartilage constructs combining time-resolved fluorescence and ultrasound imaging, Tissue Eng Part C Methods 17(4) (2011) 495-504.

[35] K.P. Mercado, M. Helguera, D.C. Hocking, D. Dalecki, Noninvasive Quantitative Imaging of Collagen Microstructure in Three-Dimensional Hydrogels Using High-Frequency Ultrasound, Tissue Eng Part C Methods 21(7) (2015) 671-82. 
[36] K.P. Mercado, M. Helguera, D.C. Hocking, D. Dalecki, Estimating cell concentration in threedimensional engineered tissues using high frequency quantitative ultrasound, Ann Biomed Eng 42(6) (2014) 1292-304.

[37] L.A. Wirtzfeld, E.S.L. Berndl, G.J. Czarnota, M.C. Kolios, Monitoring Quantitative Ultrasound Parameter Changes in a Cell Pellet Model of Cell Starvation, Biophys J 112(12) (2017) 2634-2640.

[38] M.M. Pasternak, E.M. Strohm, E.S. Berndl, M.C. Kolios, Properties of cells through life and death - an acoustic microscopy investigation, Cell Cycle 14(18) (2015) 2891-8.

[39] M.S. Gudur, R.R. Rao, A.W. Peterson, D.J. Caldwell, J.P. Stegemann, C.X. Deng, Noninvasive quantification of in vitro osteoblastic differentiation in $3 \mathrm{D}$ engineered tissue constructs using spectral ultrasound imaging, PLoS One 9(1) (2014) e85749.

[40] M. Gudur, R.R. Rao, Y.S. Hsiao, A.W. Peterson, C.X. Deng, J.P. Stegemann, Noninvasive, quantitative, spatiotemporal characterization of mineralization in three-dimensional collagen hydrogels using high-resolution spectral ultrasound imaging, Tissue Eng Part C Methods 18(12) (2012) 935-46.

[41] M.G. FL Lizzi , EJ Feleppa ,M Elbaum ,DJ Coleman, theoretical framework for spectrum analysis in ultrasonic tissue chracterisation, J Acoust Sco Am 73(4) (1983) 1366-73.

[42] F.L. Lizzi, M. Ostromogilsky, E.J. Feleppa, M.C. Rorke, M.M. Yaremko, Relationship of ultrasonic spectral parameters to features of tissue microstructure, IEEE Trans Ultrason Ferroelectr Freq Control 34(3) (1987) 319-29.

[43] E. Franceschini, R. Guillermin, Experimental assessment of four ultrasound scattering models for characterizing concentrated tissue-mimicking phantoms, J Acoust Soc Am 132(6) (2012) 3735-47.

[44] R.E. Baddour, M.D. Sherar, J.W. Hunt, G.J. Czarnota, M.C. Kolios, High-frequency ultrasound scattering from microspheres and single cells, J Acoust Soc Am 117(2) (2005) 934-43.

[45] M.L. Oelze, W.D. O'Brien, J.P. Blue, J.F. Zachary, Differentiation and Characterization of Rat Mammary Fibroadenomas and 4T1 Mouse Carcinomas Using Quantitative Ultrasound Imaging, IEEE Transactions on Medical Imaging 23(6) (2004) 764-771.

[46] M.L. Oelze, J.F. Zachary, W.D. O'Brien, Characterization of tissue microstructure using ultrasonic backscatter: Theory and technique for optimization using a Gaussian form factor, The Journal of the Acoustical Society of America 112(3) (2002) 1202-1211.

[47] J. Rouyer, T. Cueva, T. Yamamoto, A. Portal, R.J. Lavarello, In Vivo Estimation of Attenuation and Backscatter Coefficients From Human Thyroids, IEEE Trans Ultrason Ferroelectr Freq Control 63(9) (2016) 1253-1261.

[48] E. Franceschini, F.T. Yu, F. Destrempes, G. Cloutier, Ultrasound characterization of red blood cell aggregation with intervening attenuating tissue-mimicking phantoms, J Acoust Soc Am 127(2) (2010) 1104-15.

[49] E. Franceschini, B. Metzger, G. Cloutier, Forward problem study of an effective medium model for ultrasound blood characterization, IEEE Trans Ultrason Ferroelectr Freq Control 58(12) (2011) 266879.

[50] L. Kang, X. Liu, Z. Yue, Z. Chen, C. Baker, P. Winberg, G. Wallace, Fabrication and In Vitro Characterization of Electrochemically Compacted Collagen/Sulfated Xylorhamnoglycuronan Matrix for Wound Healing Applications, Polymers 10(4) (2018).

[51] K. Raum, W.D. O'Brien, Pulse-echo field distribution measurement technique for high-frequency ultrasound sources, IEEE Transactions on Ultrasonics, Ferroelectrics and Frequency Control 44(4) (1997) 810-815.

[52] L.X. Yao, J.A. Zagzebski, E.L. Madsen, Backscatter Coefficient Measurements Using a Reference Phantom to Extract Depth-Dependent Instrumentation Factors, Ultrasonic Imaging 12(1) (1990) 5870.

[53] K. Nam, I.M. Rosado-Mendez, L.A. Wirtzfeld, G. Ghoshal, A.D. Pawlicki, E.L. Madsen, R.J. Lavarello, M.L. Oelze, J.A. Zagzebski, W.D. O'Brien, Jr., T.J. Hall, Comparison of ultrasound attenuation and backscatter estimates in layered tissue-mimicking phantoms among three clinical scanners, Ultrason Imaging 34(4) (2012) 209-21. 
[54] K.I. Lee, Correlations of group velocity, phase velocity, and dispersion with bone density in bovine trabecular bone, J Acoust Soc Am 130(6) (2011) EL399-404.

[55] M.M. McCormick, E.L. Madsen, M.E. Deaner, T. Varghese, Absolute backscatter coefficient estimates of tissue-mimicking phantoms in the 5-50 MHz frequency range, J Acoust Soc Am 130(2) (2011) 737-43.

[56] D.A. Kenwright, N. Sadhoo, S. Rajagopal, T. Anderson, C.M. Moran, P.W. Hadoke, G.A. Gray, B. Zeqiri, P.R. Hoskins, Acoustic assessment of a konjac-carrageenan tissue-mimicking material at 5-60 MHZ Ultrasound Med Biol 40(12) (2014) 2895-902.

[57] R.J. Lavarello, G. Ghoshal, M.L. Oelze, On the estimation of backscatter coefficients using singleelement focused transducers, J Acoust Soc Am 129(5) (2011) 2903-11.

[58] M.F. Insana, T.J. Hall, Parametric ultrasound imaging from backscatter coefficient measurements: image formation and interpretation, Ultrason Imaging 12(4) (1990) 245-67.

[59] M.L. Oelze, W.D. O'Brien, Jr., Frequency-dependent attenuation-compensation functions for ultrasonic signals backscattered from random media, J Acoust Soc Am 111(5 Pt 1) (2002) 2308-19.

[60] M.F. Insana, R.F. Wagner, D.G. Brown, T.J. Hall, Describing small-scale structure in random media using pulse-echo ultrasound, J Acoust Soc Am 87(1) (1990) 179-92.

[61] Y. Labyed, T.A. Bigelow, A theoretical comparison of attenuation measurement techniques from backscattered ultrasound echoes, J Acoust Soc Am 129(4) (2011) 2316-24.

[62] K.J. Parker, R.C. Waag, Measurement of Ultrasonic-Attenuation within Regions Selected from BScan Images, leee T Bio-Med Eng 30(8) (1983) 431-437.

[63] R.E. Baddour, https://ieee-uffc.org/ultrasonics/software/ (Last accessed 12/2018).

[64] R.E. Baddour, M.C. Kolios, The fluid and elastic nature of nucleated cells: implications from the cellular backscatter response, J Acoust Soc Am 121(1) (2007) EL16-22.

[65] P. Muleki-Seya, R. Guillermin, J. Guglielmi, J. Chen, T. Pourcher, E. Konofagou, E. Franceschini, High-Frequency Quantitative Ultrasound Spectroscopy of Excised Canine Livers and Mouse Tumors Using the Structure Factor Model, IEEE Trans Ultrason Ferroelectr Freq Control 63(9) (2016) 13351350.

[66] M.L. Oelze, W.D. O'Brien, Defining optimal axial and lateral resolution for estimating scatterer properties from volumes using ultrasound backscatter, Journal of the Acoustical Society of America 115(6) (2004) 3226-3234.

[67] W. Liu, J.A. Zagzebski, Trade-Offs in Data Acquisition and Processing Parameters for Backscatter and Scatterer Size Estimations, leee T Ultrason Ferr 57(2) (2010) 340-352.

[68] M.L. Oelze, W.D. O'Brien, Improved scatterer property estimates from ultrasound backscatter for small gate lengths using a gate-edge correction factor, Journal of the Acoustical Society of America 116(5) (2004) 3212-3223.

[69] D.D. Klumpers, X. Zhao, D.J. Mooney, T.H. Smit, Cell mediated contraction in 3D cell-matrix constructs leads to spatially regulated osteogenic differentiation, Integr Biol (Camb) 5(9) (2013) 117483.

[70] X. Leng, B. Liu, B. Su, M. Liang, L. Shi, S. Li, S. Qu, X. Fu, Y. Liu, M. Yao, D.L. Kaplan, Y. Wang, X. Wang, In situ ultrasound imaging of silk hydrogel degradation and neovascularization, J Tissue Eng Regen Med 11(3) (2017) 822-830. 


\title{
Supporting information
}

\author{
Quantitative Ultrasound Imaging of Cell-laden Hydrogels and Printed Constructs \\ Andres Ruland, Kerry J. Gilmore, Luciana Y. Daikuara, Cormac D. Fay, Zhilian Yue, and Gordon G. \\ Wallace
}

ARC Centre of Excellence for Electromaterials Science (ACES), Intelligent Polymer Research Institute, AIIM Facility, Innovation Campus, University of Wollongong, Australia

\section{Table of contents supporting information}

Appendix 1: Details on ultrasound measurements .............................................................. 1

Appendix 2: Formulae and diagrams used for signal processing ..............................................

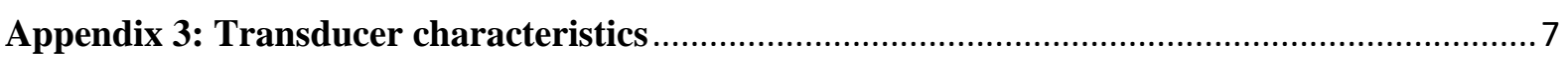

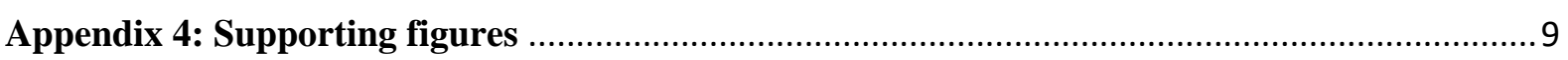

\section{Appendix 1: Details on ultrasound measurements}

All measurements were performed at room temperature. Three different procedures were used depending on the measurement purpose: reference phantom, calibration and imaging. In the case of the reference phantom, a series of measurements were required: power at focus, powerheight, thickness, speed of sound, attenuation and backscattered power.

\section{A1.1 Power measurements though media:}

Power at focus and power-height were measured with the transducer immersed in the culture media, using the bottom of the well plate as reflector and a gain of $+15 \mathrm{~dB}$. Note that the sample for the reference phantom had 4 wells, 3 for the sample and one with media only. The power measurements not only serve for the reference power spectrum, but also as the reference time to compute the thickness and speed of sound. The final power spectrum and reference time were the average of 20 random locations spaced by $200 \mu \mathrm{m}$. The power-height measurements were achieved by moving towards, and beyond, the focal point to the reflector in $40 \mu \mathrm{m}$ steps for a gate length of $16 \mathrm{PL}$, and $20 \mu \mathrm{m}$ for gate length of $8 \mathrm{PL}$. In practice, because of the small 
variation of power within the ROI, the same power spectra taken for a $16 \mathrm{PL}$ was used for the 8 PL by replicating twice the power at each height. Power-height measurements were taken at the same location, but averaging 3 different files at each height. Note that the transducer travel range and the gate length determines the height of the ROI used for QUI.

\section{A1.2 Speed of sound, thickness and attenuation:}

After returning the transducer to the focal point, it was then moved laterally to the reference phantom. First, the attenuated ultrasound pulse through the sample was measured over 40 points, spaced $200 \mu \mathrm{m}$ apart, in a rectangular raster scan. The latter served for computing the attenuation, and the time of flight of sound through the hydrogel. Due to practical limitations, only the first 13 measuring points following a straight line were included in the estimation of the speed of sound, as the culture plate and/or levelling table had a slight deviation from the precision required for time of flight measurements. The latter was crucial for accurate determination of the reference time used for calculations (see Fig. S2, Eq. S1-3). Time measurements relative to hydrogel thickness were less affected by the inconsistent orthogonal alignment between the transducer and reflector. Next, the focal point was lifted by a similar length to the hydrogel thickness (e.g. $2 \mathrm{~mm}$ ). Upon increasing the gain to $+35 \mathrm{~dB}$, the upper hydrogel edge could be detected and used as the time of flight between the transducer and the upper hydrogel edge.

\section{A1.3 Backscatter measurements on reference phantom:}

Finally, moving the transducer $1 \mathrm{~mm}$ inside the hydrogel, and gain set to $+35 \mathrm{~dB}$, the backscattered signals were recorded over the same 40 locations. Once the procedure for reference phantom method (RPM) was completed, relevant files were stored in the system and used as the internal calibration. Note that the internal calibration is only valid when measuring with the same settings (including depth of focus), same temperature and same hydrogel.

\section{A1.4. Backscatter measurements and imaging of the sample:}

In the case of calibration measurements, the signals were acquired over the test sample at 100 random positions spaced by $200 \mu \mathrm{m}$. In the case of imaging, consecutive RF scans were collected, with a spacing of $30 \mu \mathrm{m}$. For both cases, the gain was set to $+35 \mathrm{~dB}$ and the focus was located at $1 \mathrm{~mm}$ below the hydrogel surface. Data and image processing were performed in all cases after processing the complementary RPM. 


\section{Appendix 2: Formulae and diagrams used for signal processing}

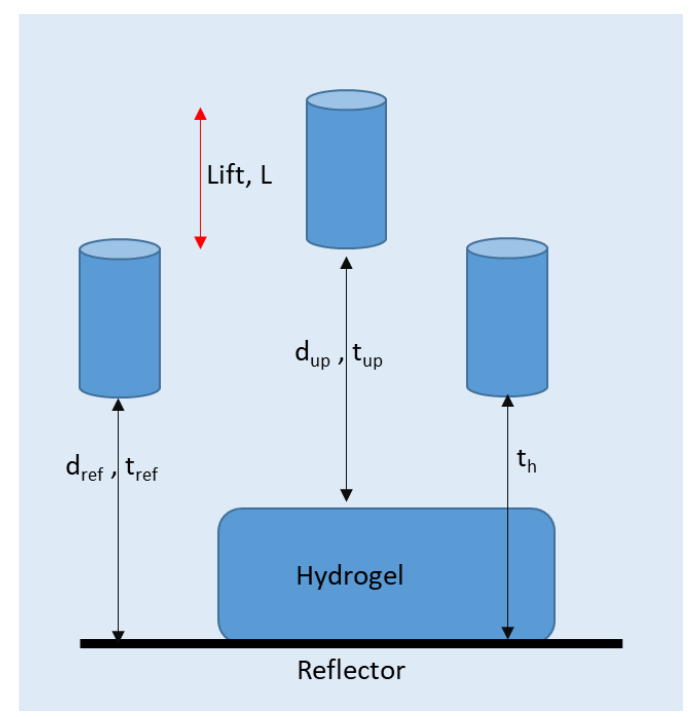

Fig. S1. Diagram illustrating the thickness and speed of sound measurements, by shifting the transducer height to the upper hydrogel edge. Abbreviations on the sketch correspond to: $d_{\text {ref }}$ and tref are the distance and time of flight between the transducer and reflector. $\mathrm{d}_{\text {up }}$ and tup are the distance and time of flight between the transducer and the upper hydrogel surface. $t_{h}$ is the time of flight between transducer and reflector though the hydrogel. Lift corresponds to the shifted axial positon of the transducer respect to $d_{\text {reff }}$.

\section{Thickness}

$$
\begin{aligned}
& \left.d_{u p}=\left[\frac{\left(t_{u p} c_{W}\right)}{2}\right]-L \quad, c_{W}=1.488,3 \mathrm{~m} / \mathrm{s} \quad \text { (Eq. } \mathrm{S} 1\right) \\
& d=d_{\text {ref }}-d_{u p}
\end{aligned}
$$

\section{Speed of sound}

$$
c=\frac{c_{W}}{1+c_{W}\left(\frac{t_{h}-t_{r e f}}{d}\right)}
$$




\section{Single point attenuation measurement and attenuation fitting equation}

$$
\begin{aligned}
& \alpha_{\mathrm{S}}(\mathrm{f})=-\frac{20}{2 \mathrm{~d}} \log \frac{\mathrm{A}_{S}(\mathrm{f})}{A_{\text {Ref }}(\mathrm{f})}+\alpha_{\mathrm{W}} f^{2}, \alpha_{\mathrm{W}}=2.1710^{-3} \mathrm{~dB} \mathrm{~cm}^{-1} \mathrm{MHz}^{-2} \\
& \alpha_{\mathrm{S}}(\mathrm{f})=\mathrm{c}_{1} \mathrm{f}+\mathrm{c}_{2} \mathrm{f}^{2}
\end{aligned}
$$
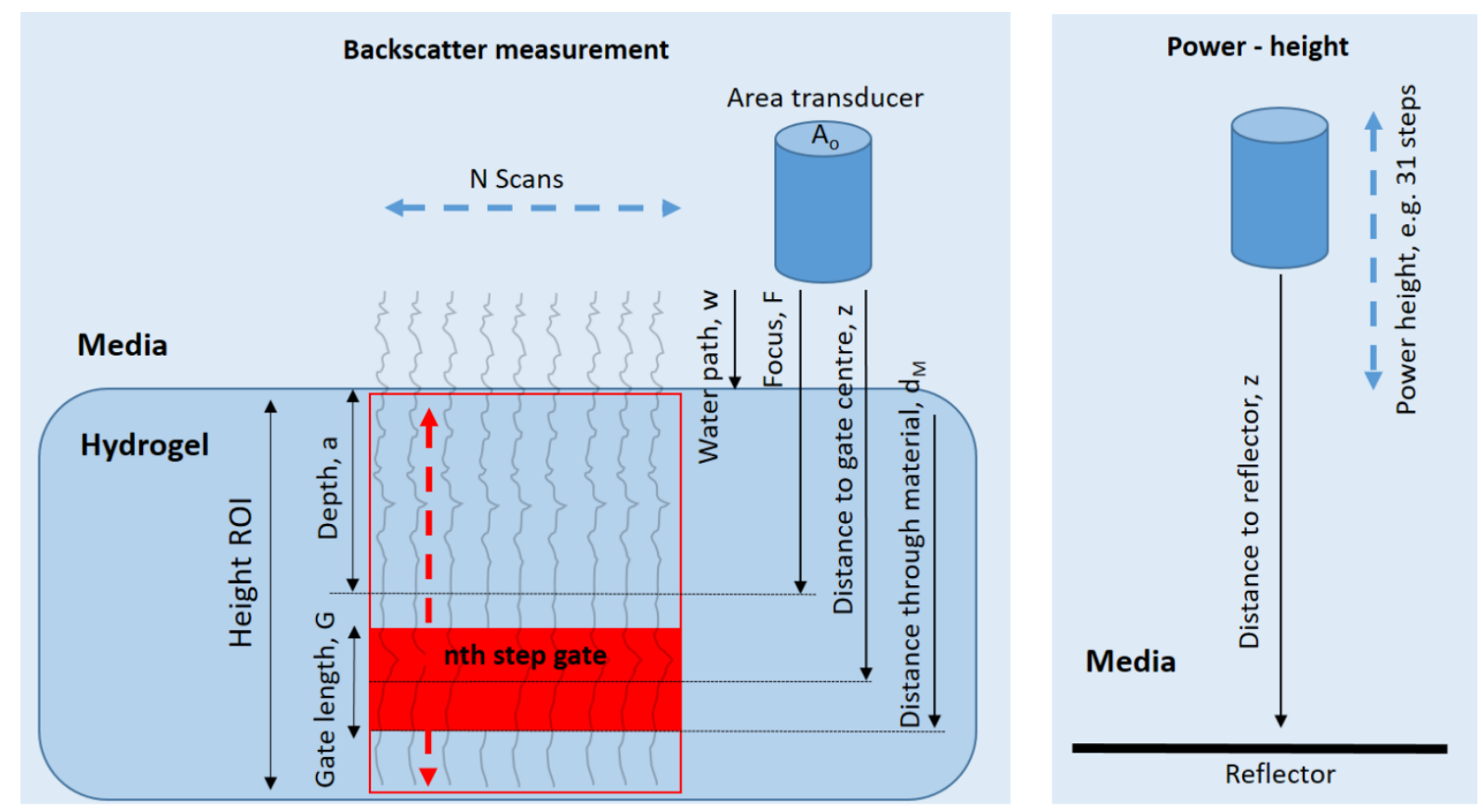

Fig. S2. Left: diagram illustrating the geometrical distances and relative positions of the transducer to a gate of depth $\mathrm{z}$ within the hydrogel. Right: illustration of power height measurement to compensate for power spectra relative to each gate depth.

\section{Backscattering coefficient of the reference phantom}

$$
\begin{aligned}
& \mathrm{BSC}_{\mathrm{R}}(\mathrm{z}, \mathrm{f})=\frac{1.45 \mathrm{z}^{2}}{\mathrm{~A}_{\mathrm{o}} \mathrm{G}} \operatorname{NPS}(\mathrm{z}, \mathrm{f}) \\
& \operatorname{NPS}(\mathrm{z}, \mathrm{f})=\frac{1}{\mathrm{~N}} \sum_{1}^{\mathrm{N}}\left(\frac{\gamma}{2}\right)^{2} \frac{\left|\mathrm{A}_{\mathrm{RPM}}\right|^{2}(\mathrm{z}, \mathrm{f})}{\left|\mathrm{A}_{\mathrm{R}_{\mathrm{Z}}}\right|^{2}(\mathrm{z}, \mathrm{f})} \mathrm{e}^{\left(4 \mathrm{~d}_{\mathrm{M}}\left(\alpha_{\mathrm{S}}(\mathrm{f})-\alpha_{\mathrm{R}}(\mathrm{f})\right)\right)} \\
& \mathrm{d}_{\mathrm{M}}=\mathrm{z}-\mathrm{w}+\frac{\mathrm{G}}{2} \quad, \mathrm{w}=\mathrm{F}-\mathrm{a} \\
& \gamma=\left(\frac{\mathrm{Z}_{\mathrm{W}}-\mathrm{Z}_{\mathrm{R}}}{\mathrm{Z}_{\mathrm{W}} \mathrm{Z}_{\mathrm{R}}}\right)^{2}, \mathrm{Z}_{\mathrm{i}}=\mathrm{c}_{\mathrm{i}} \rho_{\mathrm{i}}
\end{aligned}
$$


Local attenuation compensation by spectral difference method

$\ln \frac{\left|A_{S_{Z}}\right|^{2}(\mathrm{z}, \mathrm{f})}{\left|A_{R P M_{Z}}\right|^{2}(\mathrm{z}, \mathrm{f})}=\operatorname{ratio}(\mathrm{z}, \mathrm{f})=4 \mathrm{~d}_{\mathrm{M}} \Delta_{\alpha}+k \quad, \Delta_{\alpha}=$ slope $\quad$ (Eq. S10)

\section{Backscatter coefficient of sample using RPM}

$\operatorname{BSC}_{S}(\mathrm{z}, \mathrm{f})=\frac{1}{N_{\mathrm{av}}} \sum_{1}^{\mathrm{N}_{\mathrm{av}}} \operatorname{BSC}_{\mathrm{R}}(\mathrm{z}, \mathrm{f}) \frac{\left|\mathrm{A}_{\mathrm{z}}\right|^{2}(\mathrm{z}, \mathrm{f})}{\left|\mathrm{A}_{\mathrm{RPM}_{\mathrm{z}}}\right|^{2}(\mathrm{z}, \mathrm{f})} \mathrm{e}^{-4 \Delta_{\alpha} \mathrm{d}_{\mathrm{M}}}$

$\mathrm{BSC}_{\mathrm{T}}(\mathrm{f})=\frac{1}{\mathrm{~N}_{\mathrm{F}}} \sum_{1}^{\mathrm{N}_{\mathrm{F}}} \frac{1}{\mathrm{~N}_{\mathrm{G}}} \sum_{1}^{\mathrm{N}_{\mathrm{G}}} \mathrm{BSC}_{\mathrm{S}}(\mathrm{z}, \mathrm{f})$

$\mathrm{N}_{\mathrm{F}}=\frac{\mathrm{N}}{\mathrm{N}_{\mathrm{av}}}$

Integrated backscattering coefficient (IBC)

$\operatorname{IBC}(z)=\int_{f(B w 1(z))}^{f(B w 2(z))} \frac{B_{S C C}(z, f)}{B w_{2}(z)-B w_{1}(z)}$

(Eq. S14)

$\mathrm{IBC}_{\mathrm{T}}=\frac{1}{\mathrm{~N}_{\mathrm{F}}} \sum_{1}^{\mathrm{N}_{\mathrm{F}}} \frac{1}{\mathrm{~N}_{\mathrm{G}}} \sum_{1}^{\mathrm{N}_{\mathrm{G}}} \operatorname{IBC}(\mathrm{z})$

Size modelling

$$
\begin{aligned}
& \mathrm{MASD}=\min \left(\frac{1}{\mathrm{~m}} \sum_{1}^{\mathrm{m}}\left(\mathrm{X}_{\mathrm{i}}(\mathrm{f})-\overline{\mathrm{X}}\right)^{2}\right) \\
& \mathrm{X}_{\mathrm{i}}=10 \log \left(\frac{\mathrm{BSC}_{\mathrm{S}}(\mathrm{f})}{\mathrm{FF}_{\mathrm{i}}(\mathrm{f}) \mathrm{f}^{4}}\right) \\
& \overline{\mathrm{X}}=\frac{1}{\mathrm{~m}} \sum_{1}^{\mathrm{m}} \mathrm{X}_{\mathrm{i}} \\
& \mathrm{R}^{2}=1-\frac{\mathrm{SS}_{\text {res }}}{\mathrm{SS}_{\text {tot }}} \\
& \mathrm{SS}_{\text {res }}=\sum_{\mathrm{f}\left(\mathrm{Bw}_{1}\right)}^{\mathrm{f}\left(\mathrm{Bw}_{2}\right)}\left\|\mathrm{X}_{\mathrm{i}}(\mathrm{f})-\mathrm{X}_{\mathrm{FF}}(\mathrm{f})\right\|^{2} \\
& \mathrm{SS}_{\text {tot }}=\sum_{\mathrm{f}\left(\mathrm{Bw}_{1}\right)}^{\mathrm{f}\left(\mathrm{Bw}_{2}\right)}\left\|\mathrm{X}_{\mathrm{i}}(\mathrm{f})-\overline{\mathrm{X}}_{\mathrm{FF}}\right\|^{2}
\end{aligned}
$$




\section{Description of parameters and units per order of appearance.}

\begin{tabular}{|c|c|c|}
\hline Symbol & Units & Description \\
\hline $\mathrm{d}_{\text {up }}$ & $\mathrm{cm}$ & Distance to the hydrogel upper surface. \\
\hline$t_{\text {up }}$ & $\mathrm{s}$ & Time of travel from transducer to the hydrogel upper surface. \\
\hline $\mathrm{c}_{\mathrm{w}}$ & $\mathrm{m} / \mathrm{s}$ & Speed of sound of distilled water at room temperature. \\
\hline $\mathrm{L}$ & $\mathrm{cm}$ & Lift of transducer in distance respect to $\mathrm{d}_{\text {ref. }}$. \\
\hline$d_{\text {ref }}$ & $\mathrm{cm}$ & $\begin{array}{l}\text { Distance to reflector at focus. The reflector is any flat surface of a material } \\
\text { with known composition. }\end{array}$ \\
\hline $\mathrm{d}$ & $\mathrm{cm}$ & Hydrogel thickness. \\
\hline $\mathrm{c}$ & $\mathrm{m} / \mathrm{s}$ & Speed of sound of the hydrogel. \\
\hline$t_{h}$ & $\mathrm{~s}$ & Time of travel from transducer to reflector through the hydrogel. \\
\hline$t_{\text {ref }}$ & $\mathrm{s}$ & Time of travel from transducer to the reflector. \\
\hline$\alpha_{s}$ & $\mathrm{~dB} \mathrm{~cm}^{-1}$ & Sound attenuation as a function of frequency. \\
\hline$\alpha_{\mathrm{W}}$ & $\begin{array}{l}\mathrm{dB} \mathrm{cm} \\
\mathrm{MHz}^{-1} \\
\end{array}$ & Sound attenuation in distilled water at room temperature. \\
\hline$A_{s}$ & $\mathrm{~V}$ & $\begin{array}{l}\text { FT amplitude spectrum of the transducer pulse at the reflector through the } \\
\text { sample. FT length must be the same as used in } A_{R e f} \text {. }\end{array}$ \\
\hline$A_{\text {Ref }}$ & $\mathrm{V}$ & $\begin{array}{l}\text { FT amplitude spectrum transducer pulse at the reflector measured at } \\
\text { distance } d_{\text {ref. }}\end{array}$ \\
\hline $\mathrm{c}_{1}$ & $\begin{array}{l}\mathrm{dB} \mathrm{cm} \\
\mathrm{MHz}^{-1}\end{array}$ & First fitting coefficient of $\alpha_{s}$ \\
\hline $\mathrm{c}_{2}$ & $\begin{array}{l}\mathrm{dB} \mathrm{cm} \\
\mathrm{MHz}^{-1}\end{array}$ & Second fitting coefficient of $\alpha_{s}$. \\
\hline $\mathrm{f}$ & $\mathrm{MHz}$ & Frequency. \\
\hline $\mathrm{BSC}_{\mathrm{R}}$ & $\mathrm{sr} \mathrm{cm}^{-1}$ & $\begin{array}{l}\text { Backscattering coefficient of the reference phantom per depth, as a function } \\
\text { of frequency. The number of } \mathrm{BSC}_{\mathrm{R}} \text { as a function of depth corresponds to the } \\
\text { number of (steps }+1) \text { done in power-height measurements. }\end{array}$ \\
\hline $\mathrm{A}_{\mathrm{o}}$ & $\mathrm{cm}$ & Area transducer (active element). \\
\hline $\mathrm{G}$ & $\mathrm{cm}$ & Gate length, or length of the RF segment. \\
\hline NPS & & $\begin{array}{l}\text { Normalized power spectrum per depth, as a function of frequency. NPS is } \\
\text { the average of all scans performed on the reference phantom }(\mathrm{N}) \text {. } \\
\text { Attenuation is nepers instead of dB units. }\end{array}$ \\
\hline $\mathrm{N}$ & & Number of total scans (A-lines). N must be an even number. \\
\hline$\left|A_{\mathrm{RPM}_{\mathrm{z}}}\right|^{2}$ & $\mathrm{~W}$ & $\begin{array}{l}\text { FT power spectrum of the reference phantom corresponding to the RF } \\
\text { segment at depth z. FT is zero padded to the same number of points as } \\
\text { in }\left|A_{R z}\right|^{2}\end{array}$ \\
\hline$\left|\mathrm{A}_{\mathrm{R}_{\mathrm{z}}}\right|^{2}$ & $\mathrm{~W}$ & $\begin{array}{l}\text { FT power spectrum of the transducer response measured from a distance z } \\
\text { to the reflector. FT is zero padded to the same number of points as in } A_{R e f} \text {. }\end{array}$ \\
\hline $\mathrm{d}_{\mathrm{M}}$ & $\mathrm{cm}$ & Distance of sound travel through the sample. \\
\hline $\mathrm{z}$ & $\mathrm{cm}$ & Distance from transducer to gate centre, distance to reflector. \\
\hline $\mathrm{W}$ & $\mathrm{cm}$ & $\begin{array}{l}\text { Distance of sound travel through water path between transducer and } \\
\text { hydrogel. }\end{array}$ \\
\hline $\mathrm{F}$ & $\mathrm{cm}$ & Transducer focal point distance. \\
\hline $\mathrm{a}$ & $\mathrm{cm}$ & Depth of focal point inside sample. \\
\hline$\Upsilon$ & & Reflection coefficient. \\
\hline $\mathrm{Z}_{\mathrm{w}}$ & Mrayl & Acoustic impedance of water. \\
\hline $\mathrm{Z}_{\mathrm{R}}$ & Mrayl & Acoustic impedance of reflector. \\
\hline $\mathrm{C}_{\mathrm{i}}$ & $\mathrm{m} / \mathrm{s}$ & Speed of sound of material $i$. \\
\hline$\rho_{\mathrm{i}}$ & $\mathrm{g} \mathrm{ml}^{-1}$ & Density of material $i$. \\
\hline
\end{tabular}




\begin{tabular}{|c|c|c|}
\hline$\Delta_{\alpha}$ & $\mathrm{dB} \mathrm{cm}{ }^{-1}$ & $\begin{array}{l}\text { Differential attenuation as a function of depth, for each } \mathrm{N}_{\mathrm{F}} \text {. Determined } \\
\text { from the slope resulting from linear fitting with intercept at zero of the } \\
\text { power ratio. }\end{array}$ \\
\hline $\mathrm{k}$ & & Constant parameter. \\
\hline$\left|\mathrm{A}_{\mathrm{S}_{\mathrm{z}}}\right|^{2}$ & $\mathrm{~W}$ & $\begin{array}{l}\text { Fourier transform (FT) in amplitude of the sample corresponding to the RF } \\
\text { segment at depth z. FT is zero padded to the same number of points as } \\
\text { in }\left|A_{R P M_{Z}}\right|^{2} \text {. }\end{array}$ \\
\hline $\mathrm{BSC}_{\mathrm{S}}$ & $\mathrm{sr} \mathrm{cm}^{-1}$ & $\begin{array}{l}\text { Backscattering coefficient of the sample per } \mathrm{N}_{\mathrm{av}} \text {, per depth, as a function of } \\
\text { frequency, for each } \mathrm{N}_{\mathrm{F}} \text {. }\end{array}$ \\
\hline $\mathrm{N}_{\mathrm{av}}$ & & Number of averaged scans per lateral pixel. \\
\hline $\mathrm{BSC}_{\mathrm{T}}$ & $\mathrm{sr} \mathrm{cm}^{-1}$ & $\begin{array}{l}\text { Averaged } \mathrm{BSC}_{\mathrm{s}} \text { for all gates, and for all pixels laterally, as a function of } \\
\text { frequency. }\end{array}$ \\
\hline $\mathrm{N}_{\mathrm{G}}$ & & Number of gates or RF segments per scan. \\
\hline $\mathrm{N}_{\mathrm{F}}$ & & Number of lateral pixels. \\
\hline IBC & $\mathrm{sr} \mathrm{cm}^{-1}$ & $\begin{array}{l}\text { Integrated backscattering coefficient per depth, for each } \mathrm{N}_{\mathrm{F}} \text {. A single } \\
\text { numerical value of } \mathrm{BSC}_{\mathrm{S}} \text {. }\end{array}$ \\
\hline $\mathrm{Bw}_{1}$ & $\mathrm{MHz}$ & $\begin{array}{l}\text { Lower limit of }-6 \mathrm{~dB} \text { frequency interval at depth z. Extracted from power } \\
\text { height measurements. }\end{array}$ \\
\hline $\mathrm{Bw}_{2}$ & $\mathrm{MHz}$ & $\begin{array}{l}\text { Upper limit of }-6 \mathrm{~dB} \text { frequency interval at depth z. Extracted from power } \\
\text { height measurements. }\end{array}$ \\
\hline $\mathrm{IBC}_{\mathrm{T}}$ & $\mathrm{sr} \mathrm{cm}^{-1}$ & $\begin{array}{l}\text { Averaged IBC for all gates, and all pixels laterally. A final single numerical } \\
\text { value out of } \mathrm{N} \text { scans and } \mathrm{G} \text { gates. }\end{array}$ \\
\hline MASD & & Minimum averaged squared difference. \\
\hline $\mathrm{m}$ & & Number of frequency points between Bw1 and Bw1. \\
\hline $\mathrm{X}_{\mathrm{i}}$ & $\mathrm{dB}$ & $\begin{array}{l}\text { Ratio between the measured BSC expressed as FF units, and the modelled } \\
\text { FF corresponding to size } i \text {. The ratio value at Bw1 is set to zero. }\end{array}$ \\
\hline $\mathrm{FF}_{\mathrm{i}}$ & & $\begin{array}{l}\text { Each of the modelled FFs given by the theoretical model (e.g. Anderson } \\
\text { model). }\end{array}$ \\
\hline$\overline{\mathrm{X}}$ & $\mathrm{dB}$ & The averaged $\mathrm{Xi}$ for all frequencies within Bw1 and Bw2. \\
\hline $\mathrm{SS}_{\text {res }}$ & $\mathrm{dB}$ & $\begin{array}{l}\text { Residual sum of squares for all intervening frequencies. The absolute } \\
\text { squared difference of each } X_{i} \text { relative to } X_{F F} \text {. }\end{array}$ \\
\hline $\mathrm{X}_{\mathrm{FF}}$ & $\mathrm{dB}$ & The ratio of measured BSC with the FF that returned the minima MASD. \\
\hline $\mathrm{SS}_{\text {tot }}$ & $\mathrm{dB}$ & $\begin{array}{l}\text { Total sum of squares for all intervening frequencies. The absolute squared } \\
\text { difference of each } X_{i} \text { relative to averaged } X_{F F} \text { along its frequency values. }\end{array}$ \\
\hline $\mathrm{R}^{2}$ & & $\begin{array}{l}\text { Coefficient of determination between experimental BSC and its } \\
\text { corresponding modelled scatter size. }\end{array}$ \\
\hline
\end{tabular}

\section{Appendix 3: Transducer characteristics}

$$
\begin{array}{ll}
\lambda=\frac{\mathrm{C}_{\mathrm{w}}(\mu \mathrm{s} / \mathrm{mm})}{\mathrm{f}_{\mathrm{C}}(\mathrm{MHz})} & \text { (Eq. S22) } \\
\mathrm{f}^{\#}=\frac{\mathrm{f}_{1}}{\mathrm{~A}_{\mathrm{d}}} & \text { (Eq. S23) } \\
\mathrm{D}_{\text {lat }}=1.028 \lambda \mathrm{f}^{\#} & \text { (Eq. S24) } \\
\mathrm{D}_{\mathrm{ax}}=\frac{\mathrm{c}_{\mathrm{w}} \tau}{2} & \text { (Eq. S25) }
\end{array}
$$


Table S1. Transducer characteristics

\begin{tabular}{|l|l|}
\hline Bandwidth $-6 \mathrm{~dB}(\mathrm{MHz})$ & $14.30-46.80$ \\
\hline Pulse length $-6 \mathrm{~dB}, \tau(\mathrm{ns})$ & 48.80 \\
\hline Acoustic wavelength, $\lambda(\mu \mathrm{m})$ & 48.60 \\
\hline Center frequency, $\mathrm{f}_{\mathrm{c}}(\mathrm{MHz})$ & 30.60 \\
\hline Axial resolution, $\mathrm{D}_{\mathrm{ax}}(\mu \mathrm{m})$ & 36.30 \\
\hline Lateral resolution, $\mathrm{D}_{\mathrm{lat}}(\mu \mathrm{m})$ & 127.00 \\
\hline Depth of view $(\mathrm{mm})$ & 2.10 \\
\hline Transducer diameter, $\mathrm{Add}_{\mathrm{d}}(\mathrm{mm})$ & 6.00 \\
\hline Focal length, $\mathrm{f}_{\mathrm{l}}(\mathrm{mm})$ & 15.25 \\
\hline F number, $\mathrm{f}^{\#}$ & 2.54 \\
\hline
\end{tabular}

a)

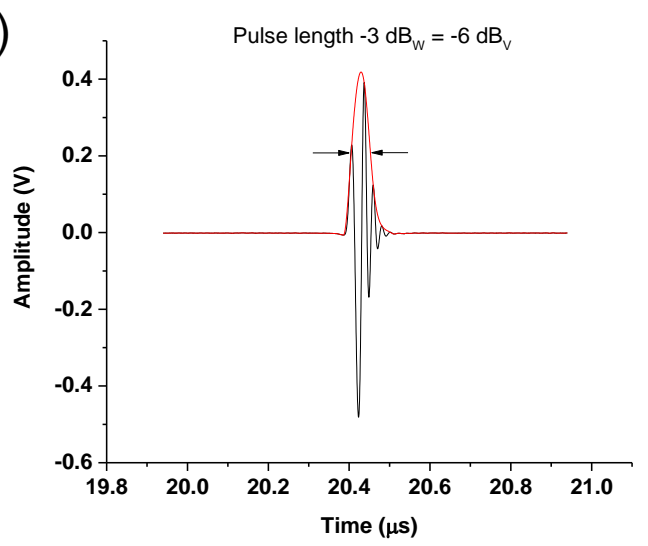

b)

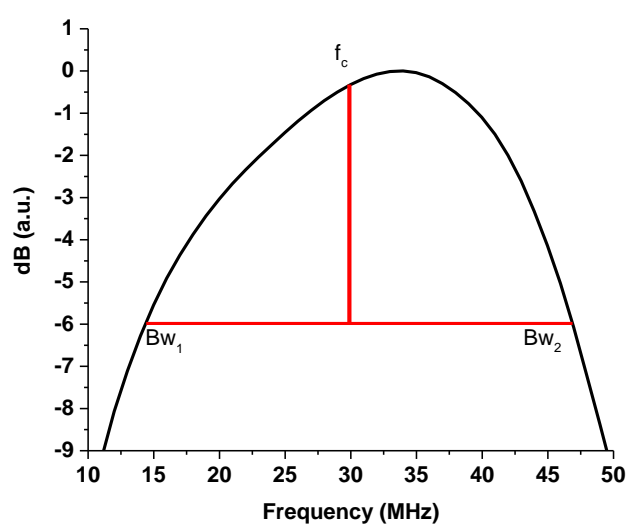

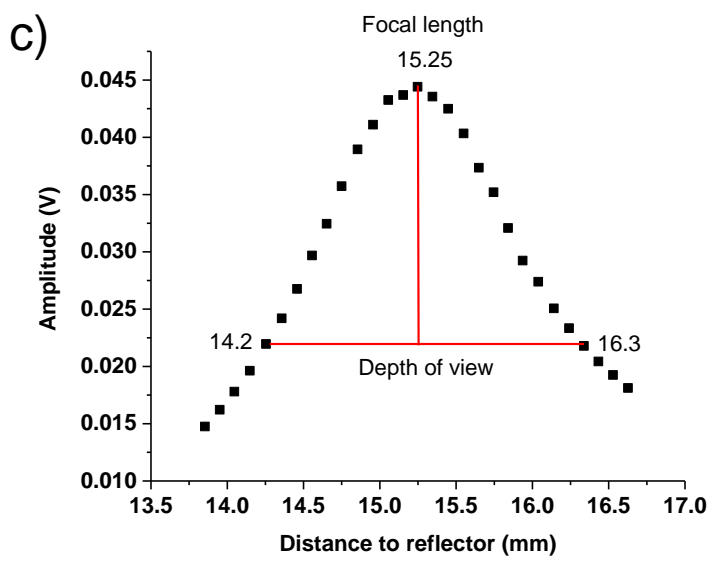

Fig. S3. a) Pulse length measurement of the transducer response at the focal point, measured on a flat reflector. b) Corresponding FT of the transducer pulse at the focal point. c) Measurement of depth of view by recording the FT amplitude maxima of the transducer pulse as a function of distance to a reflector (polystyrene surface). 


\section{Appendix 4: Supporting figures}

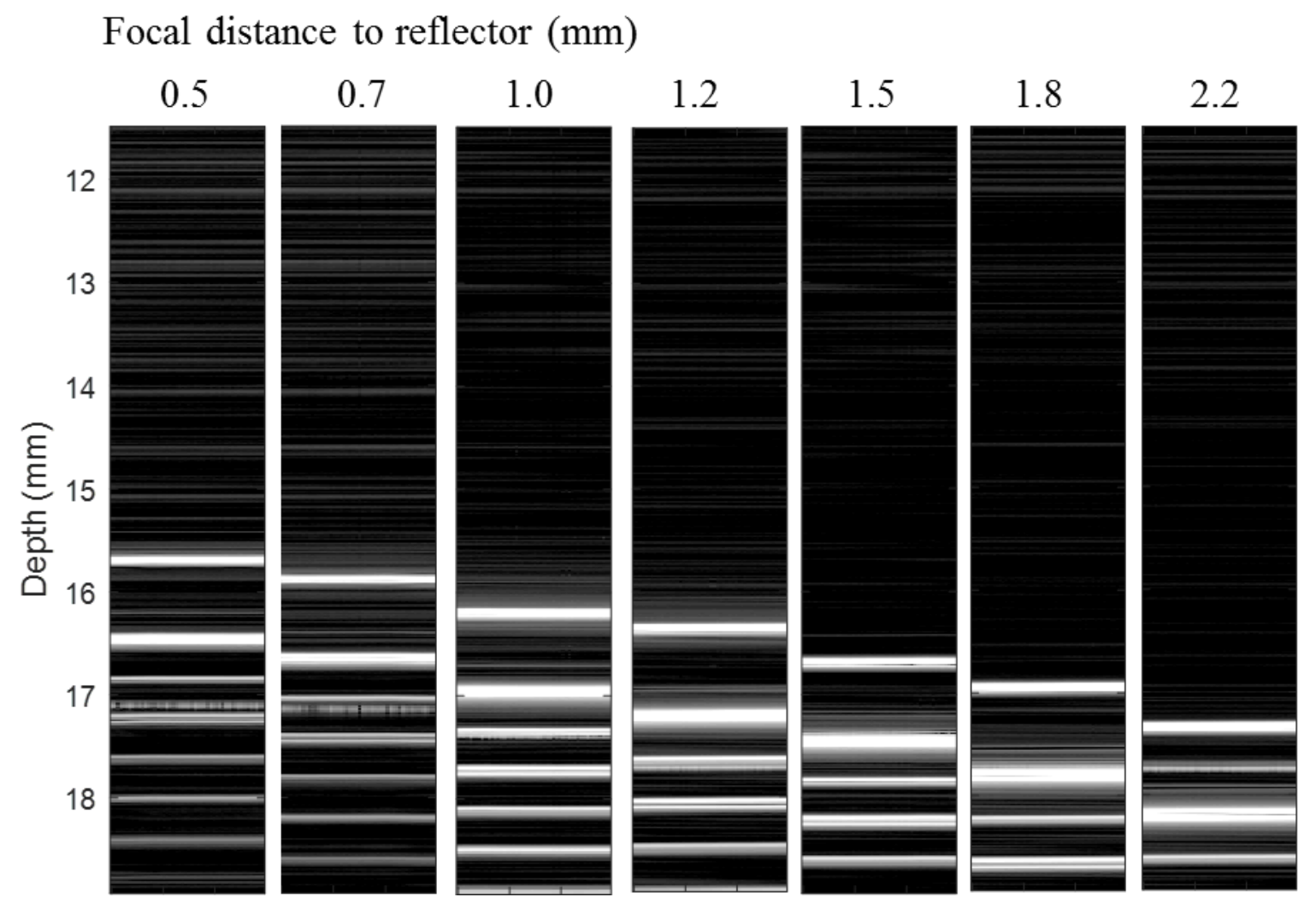

Fig. S4. Sequence of greyscale images as a function of the focal distance to reflector, measured in water. From top to bottom, the first intense reflection corresponds to the bottom of the well plate. Acoustic interferences can be seen as grey horizontal lines which are artefacts along the acoustic path. Acoustic interferences dissipate as the focal distance to reflector is increased. 


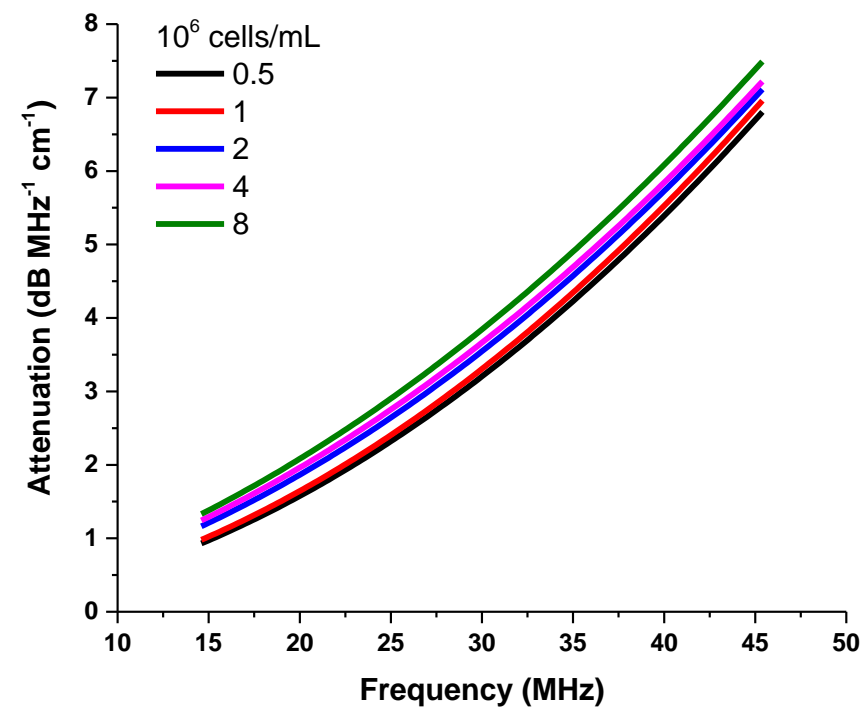

Fig. S5. Fitted attenuation spectra within the $-6 \mathrm{~dB}$ frequency interval for each of the investigated cell densities in PC12 cell-laden hydrogels. The averaged $\mathrm{R}^{2}$ and standard deviation using the attenuation fitting function (Eq. S5) for each cell density $(n=10)$ resulted in: 0.5: $\left(0.999 \pm 3.35 \times 10^{-4}\right), 1:\left(0.998 \pm 3.88 \times 10^{-4}\right), 2:\left(0.998 \pm 7.22 \times 10^{-4}\right), 4:\left(0.996 \pm 2.35 \times 10^{-}\right.$ $\left.{ }^{3}\right)$, 8: $\left(0.997 \pm 1.67 \times 10^{-3}\right)$. Fitting coefficients $(\mathrm{C} 1, \mathrm{C} 2): 0.5:(0.0228,0.0028), 1:(0.0262$, 0.0028), 2:(0.0432, 0.0025),4:(0.0501, 0.0024), 8:(0.0561, 0.0024). Single point attenuation measurements performed on set 3 , replica 3 .

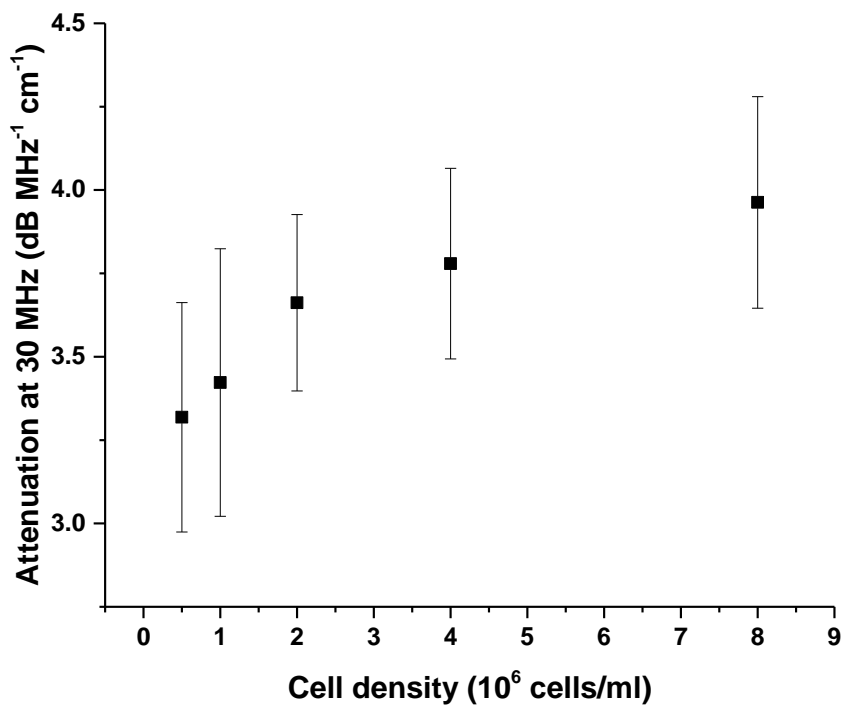

Fig. S6. Attenuation at center frequency of Fig. S4 as a function of cell density. Data points correspond to the fitted averaged attenuation $(n=10)$ at each cell density, with error bars as the standard deviation for each individual fitting function. 


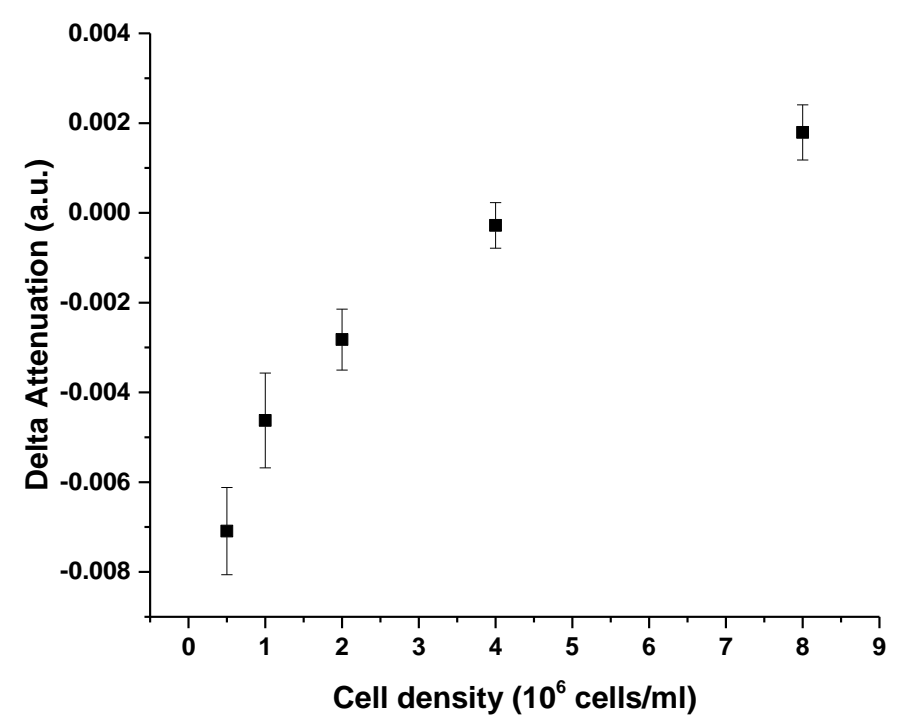

Fig. S7. Differential attenuation relative to the reference phantom (set 3) determined by the spectral difference method, as a function of cell density. Error bars represent the standard deviation of $\Delta \alpha$ for all gates (8) after averaging 100 scans with $200 \mu \mathrm{m}$ spacing. Data corresponding to set 3 , replica 3 .

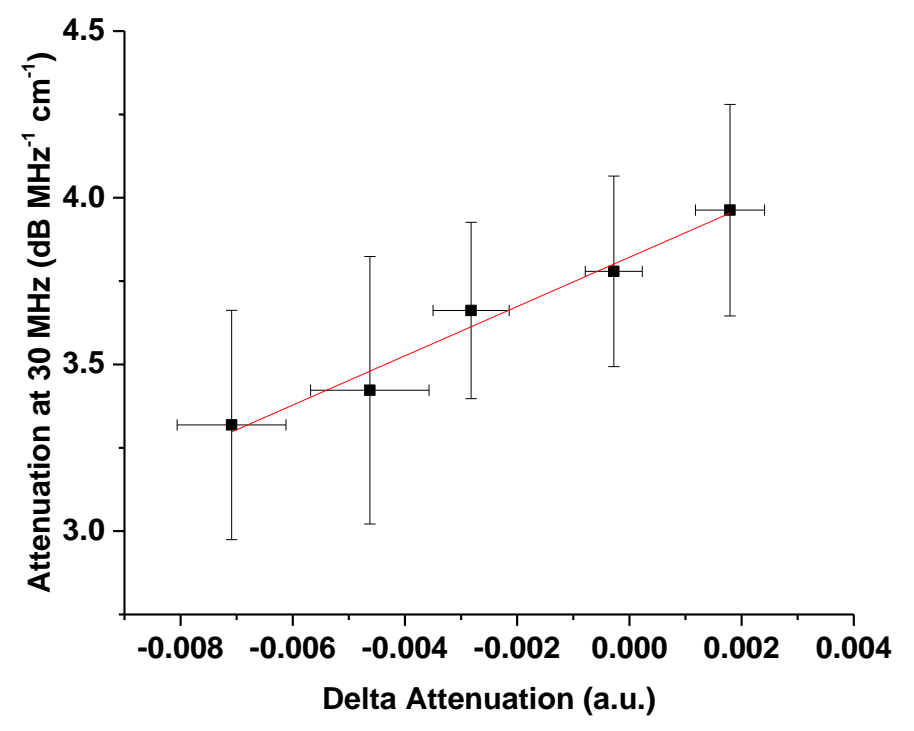

Fig. S8. Comparison of the measured attenuation using single point measurements together with the differential attenuation determined by the spectral difference method. The standard deviations for each of the measurements are included as error bars. The linear regression coefficient between both is $\mathrm{R}^{2}=0.967$. Data comparison for set 3, replica 3 . 


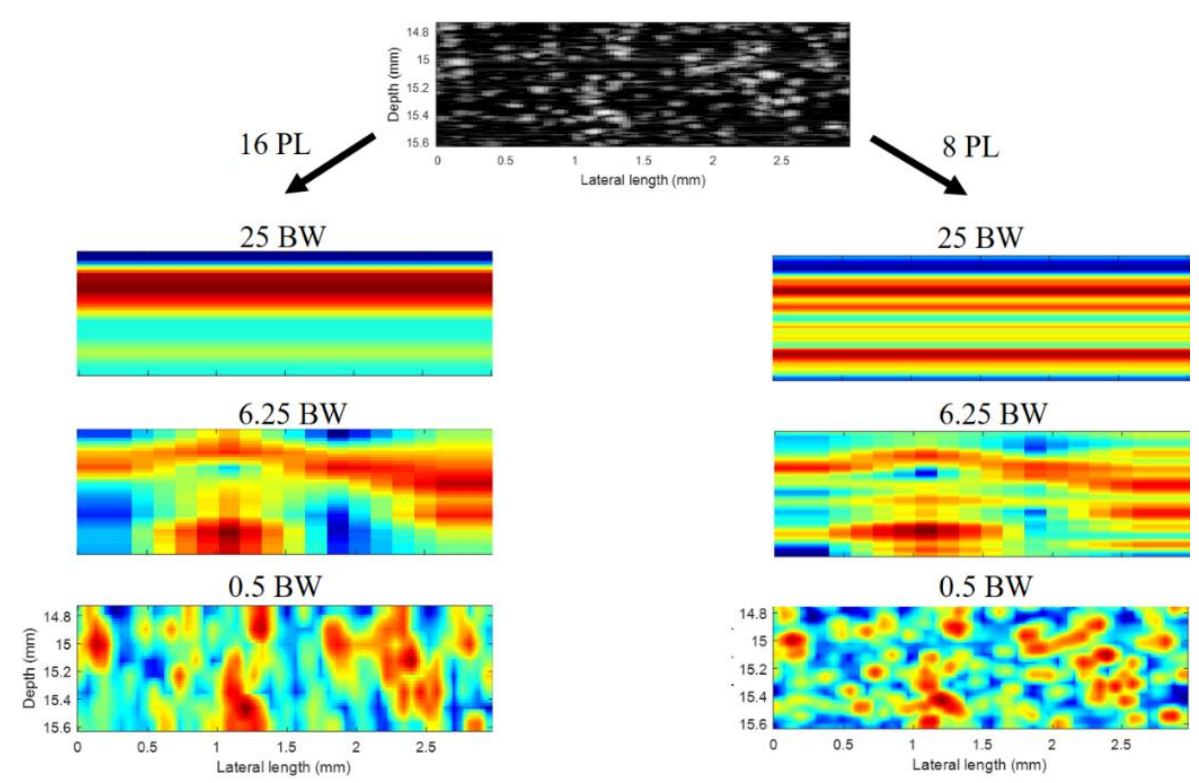

Fig. S9. Effect of IBC image resolution as a function of pixel size. Top center image: Raw greyscale image. Left and right columns: processed at pulse length (PL) of 16 and 8, respectively. Within each pulse length, the lateral averaging was changed from 25, 6.25 and $0.5 \mathrm{BW}$, corresponding to 100,25 and $2 \mathrm{RF}$ lines recorded with $30 \mu \mathrm{m}$ in spacing.

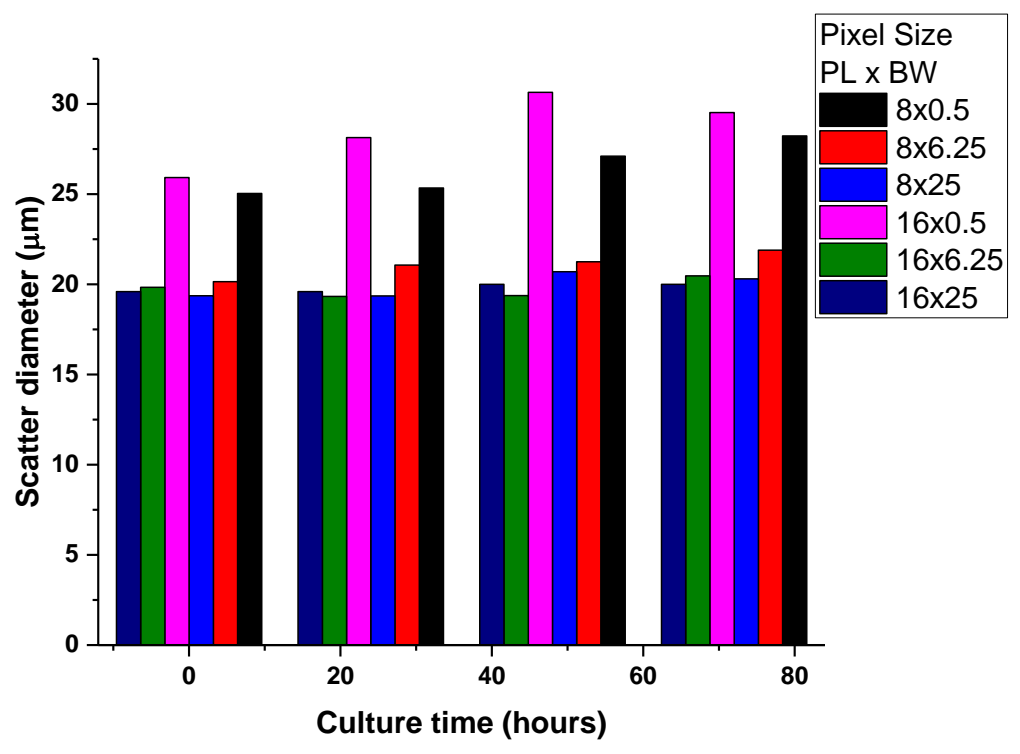

Fig S10. Modelled averaged scatter dimeter as a function of pixel size and culture time. 
a)

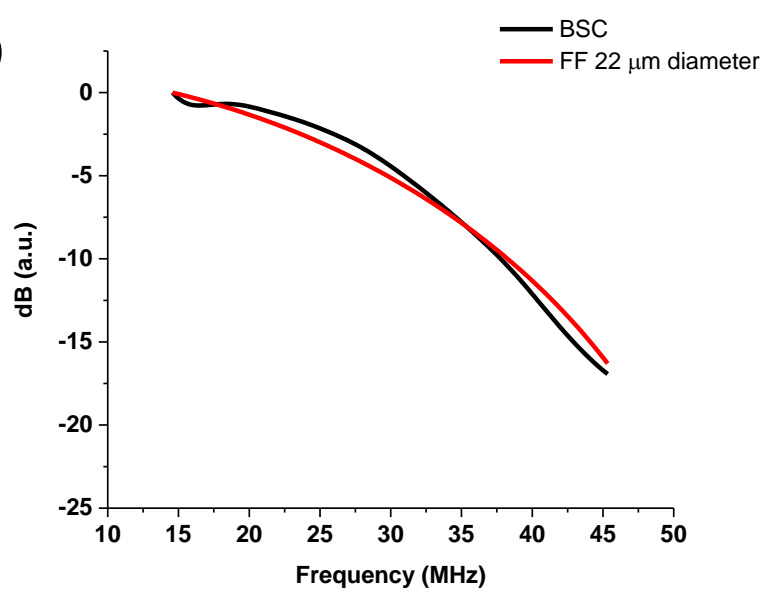

b)

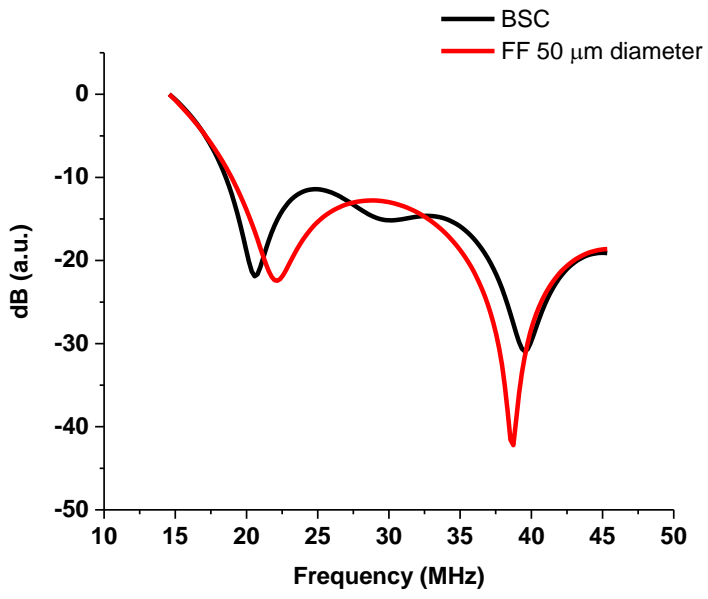

c)

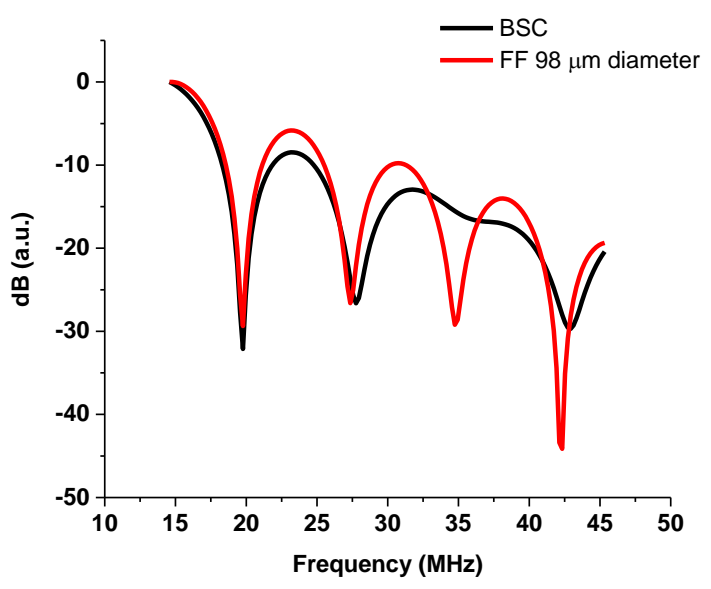

Fig. S11. Examples of scatter size estimation by fitting modelled FFs (red) to experimental BSC spectra (black) expressed as form factors (Eq. S17). Spectra set to zero at frequency Bw1. a) Scatter size of $22 \mu \mathrm{m}$. b) scatter size of $50 \mu \mathrm{m}$, c) scatter size of $98 \mu \mathrm{m}$ in diameter. The fitting coefficient $\mathrm{R}^{2}$, between BSC and FF for each example correspond to, $a=0.967 ; b=$ $0.941 ; \mathrm{c}=0.935$. 


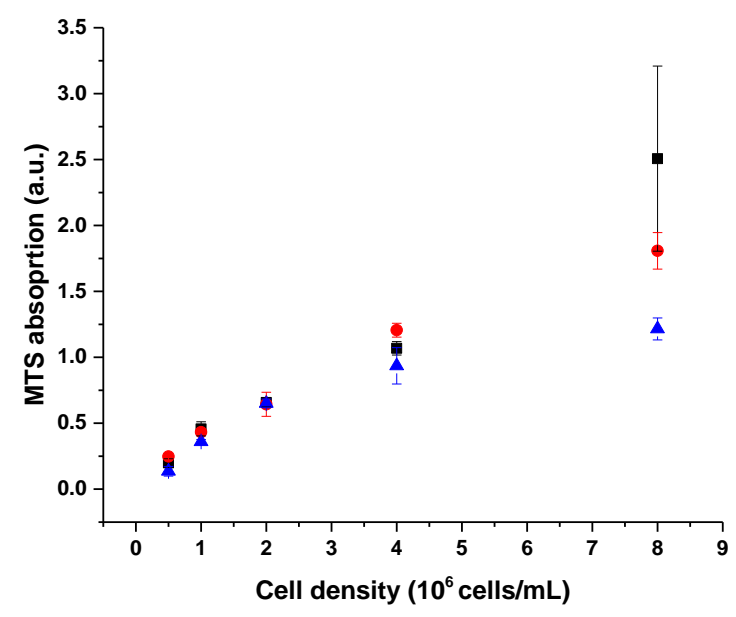

Fig. S12. Calibration of MTS absorbance as a function of cell density, for each of the 3 independent datasets. Set 1: squares $\left(0.5-4.0 \times 10^{6}\right.$ cells $\left./ \mathrm{mL}\right)$, set 2: circles, set 3: triangles. MTS absorption expressed as the averaged values $(n=3)$ at each cell density including the standard deviation across replicates.

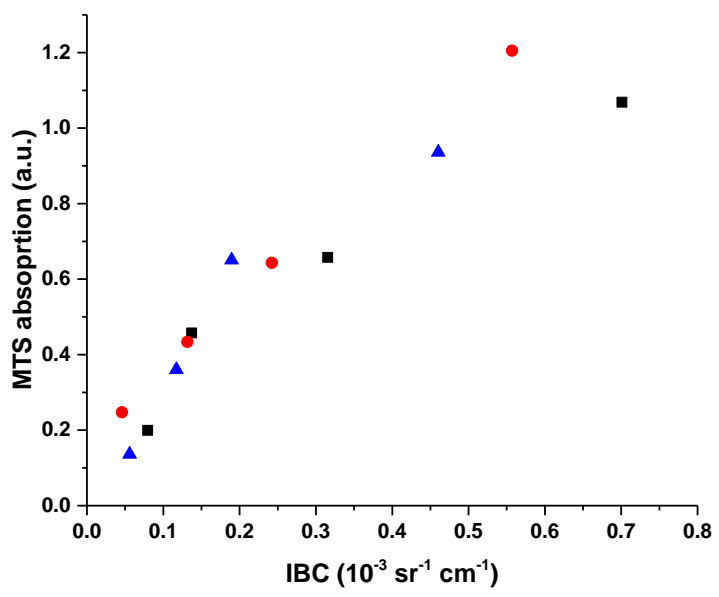

Fig. S13, Comparison of averaged IBC and averaged MTS values per cell density, for each of the calibration sets, from $0.5-4.0 \times 10^{6}$ cells $/ \mathrm{mL}$. Set 1 : squares, set 2: circles, set 3: triangles. 


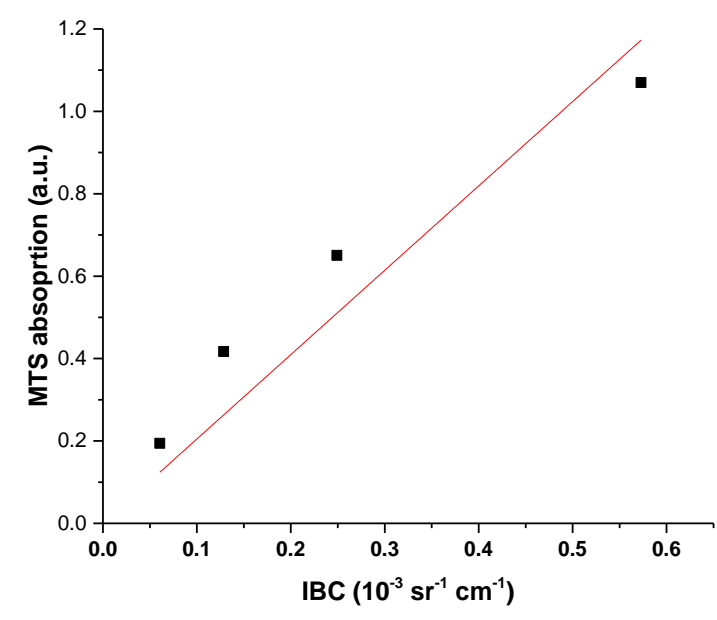

Fig. S14. Linear fit of the averaged IBC and MTS relationship at each cell density for the interval from $0.5-4.0 \times 10^{6}$ cells $/ \mathrm{ml} . \mathrm{R}^{2}=0.956$, slope $=2047.56$.

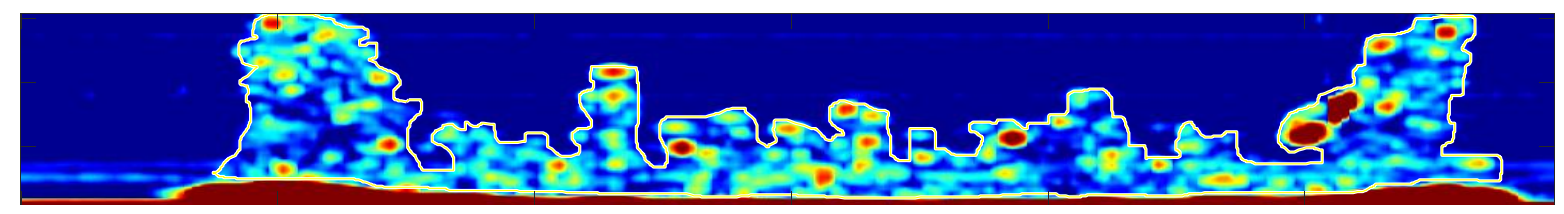

Fig. S15. Example for the selection of the bioprinted construct area used for extracting the averaged cell density per scan plane. Performed by freehand selection imfreehand (MATLAB). 